A Visible/Near-IR Spectral Database for Plutonium Solutions of Known Nitric Acid, Fluoride, and Oxalate Composition

Roderick S. Day

Alvin R. Vigil

S. Fredric Marsh

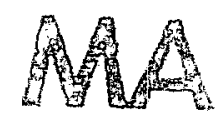

L) 1 


\section{DISCLAIMER}

This report was prepared as an account of work sponsored by an agency of the United States Government. Neither the United States Government nor any agency Thereof, nor any of their employees, makes any warranty, express or implied, or assumes any legal liability or responsibility for the accuracy, completeness, or usefulness of any information, apparatus, product, or process disclosed, or represents that its use would not infringe privately owned rights. Reference herein to any specific commercial product, process, or service by trade name, trademark, manufacturer, or otherwise does not necessarily constitute or imply its endorsement, recommendation, or favoring by the United States Government or any agency thereof. The views and opinions of authors expressed herein do not necessarily state or reflect those of the United States Government or any agency thereof. 


\section{DISCLAIMER}

Portions of this document may be illegible in electronic image products. Images are produced from the best available original document. 


\title{
A VISIBLE/NEAR-IR SPECTRAL DATABASE FOR PLUTONIUM SOLUTIONS OF KNOWN NITRIC ACID, FLUORIDE, AND OXALATE COMPOSITION
}

\author{
by
}

\author{
Roderick S. Day, Alvin R. Vigil, \\ and S. Fredric Marsh
}

\begin{abstract}
Fluoride and oxalate are common components of plutonium process solutions. Unfortunately, these anions form highly stable complexes that interfere in many plutonium process operations. Knowledge of the fluoride and oxalate content of process solutions may allow appropriate corrective action to be taken to prevent such interference. On-line spectrophotometry, which is being developed to monitor process solutions at the Los Alamos Plutonium Facility, has the potential to detect and estimate the concentration of these two anions and other solution constituents when the spectral data are processed using chemometric techniques. Spectra of 126 solutions that contained known concentrations of plutonium, fluoride, oxalate, and nitric acid were acquired as a database for on-line spectrophotometry. These spectra and a discussion of their unique spectral features are presented.
\end{abstract}

\section{INTRODUCTION}

Because anionic impurities that form highly stable complexes with plutonium are known to interfere in the nitrate anion exchange process, ${ }^{1}$ it is essential that the concentration of such impurities be measured. Important components in an operating chemical process have traditionally been determined by withdrawing individual process samples, which then are transferred to an isolated laboratory for analysis. Analytical information obtained in this way typically is received far too late to impact process operational decisions. More recently, however, we have attempted to decrease the time lag and cost of such analyses by installing online or at-line analytical instruments that can provide rapid assay of important process parameters. Such real-time or near-real-time measurements are part of a new discipline known as Process Analytical Chemistry that has developed to meet this growing need. ${ }^{2}$

An important tool of Process Analytical Chemistry is a multivariate statistical analysis technique known as Chemometrics. As stated by Callis et al.,"

"In this method, the computer is provided with a training set consisting of both the spectrum of each of the samples and the corresponding set of properties measured by an independent reference method. It is important that the training set consist of representative samples whose variation spans that of the set of all samples which might reasonably be encountered by the method. Once the data set is acquired, the computer searches for correlations between the spectra and the sought-for property. Eventually, a transformation vector is produced that, when 
multiplied by the spectral vector, yields an estimate for the property."

A major objective of our work was to provide a comprehensive "training set" for subsequent Chemometric processing, as described above, suitable for application to the analysis of process solutions by on-line spectrophotometry. Another purpose of this work was to provide previously unavailable, detailed spectra showing the effects of known quantities of fluoride or oxalate on plutonium in specified concentrations of nitric acid. Although only graphical presentations are included in this report, the authors also have all spectral data in digital form and will provide them to interested researchers on request.

\section{REAGENTS AND APPARATUS}

The plutonium used in this study was purified by nitrate anion exchange and converted completely to $\mathrm{Pu}(\mathrm{IV})$ by hydrogen peroxide. ${ }^{3}$ The absence of other oxidation states was confirmed by spectrophotometric assay.

Reagent grade nitric acid was used as received.

Reagent grade hydrofluoric acid was used as received.

Reagent grade oxalic acid was used as received.

Deionized water with a resistivity of at least 17 megohms-centimeter was used to prepare all aqueous solutions.

All aqueous solutions were prepared in advance to contain all components except plutonium. When 0.5 milliliter of $\mathrm{Pu}(\mathrm{IV})$ stock solution in $7 \mathrm{M}$ nitric acid was added, the target concentrations of all components were obtained. The $\mathrm{Pu}(\mathrm{IV})$ stock solution was added to the prepared solutions and mixed thoroughly immediately before each spectral measurement to minimize the possibility that other oxidation states of plutonium might be formed by disproportionation or complexation reactions.

All spectra were taken on a Quantum 1200 spectrophotometer, obtained from $\mathrm{L} T$ Industries, Rockville, Maryland.

\section{EXPERIMENTAL}

\section{Plutonium}

Two levels of plutonium concentration, 2 grams per liter or 10 grams per liter, were included in this study. Spectrophotometric measurements were acquired for these two solutions using 10 - and 2-millimeter pathlength cells, respectively, to obtain similar experimental absorbance readings.

\section{Fluoride}

Sufficient hydrofluoric acid was added to provide fluoride/plutonium atom ratios of $0,1,2,3$, and 4 in the 2 grams plutonium per liter solutions. Identical quantities of hydrofluoric acid were added to the 10 gram plutonium per liter solutions, which provided fluoride/plutonium atom ratios of $0,0.2,0.4,0.6$, and 0.8 in those solutions.

\section{Oxalate}

Sufficient oxalic acid was added to provide oxalate/plutonium mole ratios of $0,0.5,1,1.5$, and 2 in the 2 grams plutonium per liter solutions. Identical quantities of oxalic acid were added to the 10 gram plutonium per liter solutions, which provided oxalate/plutonium mole ratios of $0,0.1,0.2,0.3$, and 0.4 in those solutions.

\section{Nitric Acid}

Each combination of plutonium and fluoride or plutonium and oxalate described above was prepared in nitric acid concentrations of $4,5,6,7,8,9$, and $10 M$. In addition to the specified nitric acid concentrations, some solutions contained additional small quantities of acid as either hydrofluoric or oxalic acid.

\section{Spectrophotometric Measurements and Base- line Normalization}

All spectra were acquired on an $\mathrm{L} T$ Industries Quantum 1200 scanning spectrophotometer over the range of 400 to 880 nanometers. Twenty repetitive spectra of each solution were acquired and averaged to improve the signal/ noise ratio.

Before individual spectra were assembled in sets to show the effects of changing a single variable, all spectra were normalized to eliminate the effect of occasional baseline shifts. Because the 520nanometer absorbance region was least affected by changes in solution composition, it was selected as the normalization wavelength. Absorbance values at 520 nanometers were plotted as a function of nitric acid concentration for each of the two plutonium concentrations. After eliminating obvious outliers, these plots showed a slight increase in absorption with increasing nitric acid concentration, but no characteristic trends from the other anions. 
An average absorption at 520 nanometers at each nitric acid concentration (for each plutonium concentration) was calculated and each set of these averages was fit to a least-squares line (Fig. 1). The absorbance value of each individual spectrum at 520 nanometers was then compared to the least-squares value for the appropriate nitric acid concentration, and the entire spectrum was raised or lowered to achieve agreement at this wavelength. Only then were individual spectra combined into the threedimensional presentations included in this report as Figs. 5 through 34 .

\section{RESULTS AND DISCUSSION}

The presence of a specified quantity of fluoride is known to have a greater interfering effect on the sorption of $\mathrm{Pu}(\mathrm{IV})$ on anion exchange resin than the effect of an equivalent quantity of oxalate. This difference has been quantified by measuring the distribution coefficients of $\mathrm{Pu}(\mathrm{IV})$ from all aqueous media included in this study. ${ }^{2}$ Similarly, the presence of a specified quantity of fluoride was found to perturb the spectra of $\mathrm{Pu}(\mathrm{IV})$ in nitric acid significantly more than is true for an equivalent quantity of oxalate.

\section{EFFECTS OF NITRIC ACID, FLUORIDE, AND OXALATE ON THE DISTRIBUTION COEFFICIENT OF $\mathrm{Pu}(\mathrm{IV})$ ON ANION EXCHANGE RESIN}

Figure 2 shows the distribution coefficient of $\mathrm{Pu}(\mathrm{IV})$ onto Lewatit ${ }^{T M}$ MP-500-FK strong-base

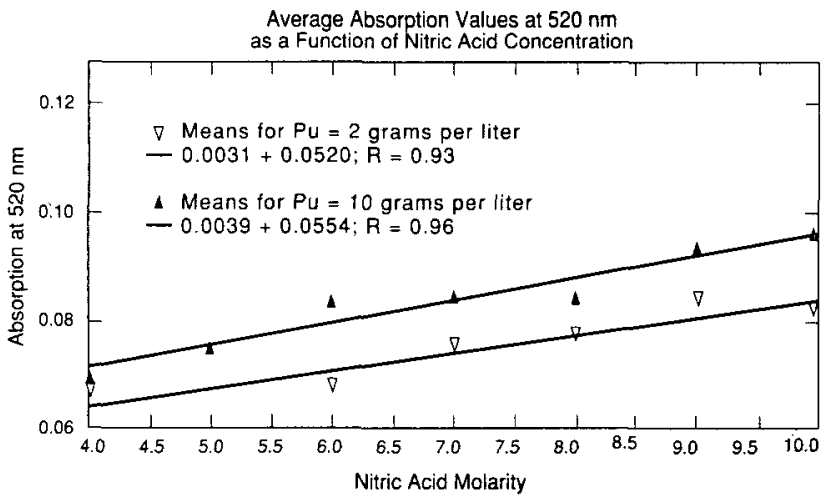

Fig. 1. Least-squares fit of averaged absorption values at 520 nanometers, as a function of nitric acid concentration, for solutions of 2 grams $\mathrm{Pu}$ per liter and 10 grams Pu per liter. anion exchange resin as a function of nitric acid concentration and fluoride-to-plutonium ratios of zero to 4. The largest decrease in $\mathrm{Pu}(\mathrm{IV})$ sorption is seen for the first equivalent of fluoride added; thereafter each equivalent of fluoride causes a smaller but approximately equal decrease in the distribution coefficient.

Figure 3 shows the distribution coefficient of $\mathrm{Pu}(\mathrm{IV})$ onto Lewatit ${ }^{T M}$ MP-500-FK strong-base anion exchange resin as a function of nitric acid concentration and fluoride-to-plutonium ratios of zero to 0.8 . The largest decrease in $\mathrm{Pu}(\mathrm{IV})$ sorption is again seen for the first portion of fluoride added; thereafter each additional increment causes a smaller decrease in the distribution coefficient. The convergence of the distribution coefficient curves for the three highest fluoride levels at the highest concentrations of nitric acid may be caused by successful competition for plutonium by the higher levels of nitrate and by protonation of the fluoride.

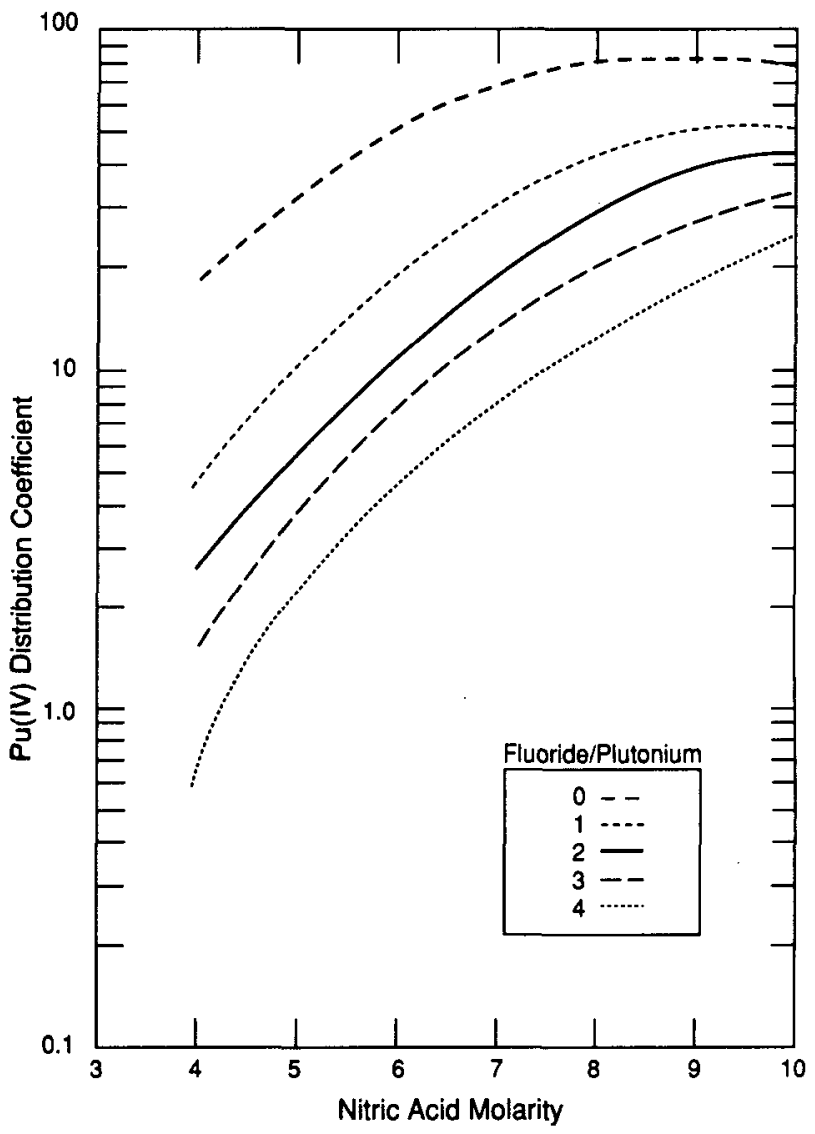

Fig. 2. Effect of nitric acid concentration and fluoride/Pu ratio on the distribution coefficient of $\mathrm{Pu}$ (IV) onto strong-base anion exchange resin ( $\mathrm{F} / \mathrm{Pu}=0$ to $4, \mathrm{Pu}$ loading $=20$ grams per liter resin, dynamic contact period $=15$ minutes). 


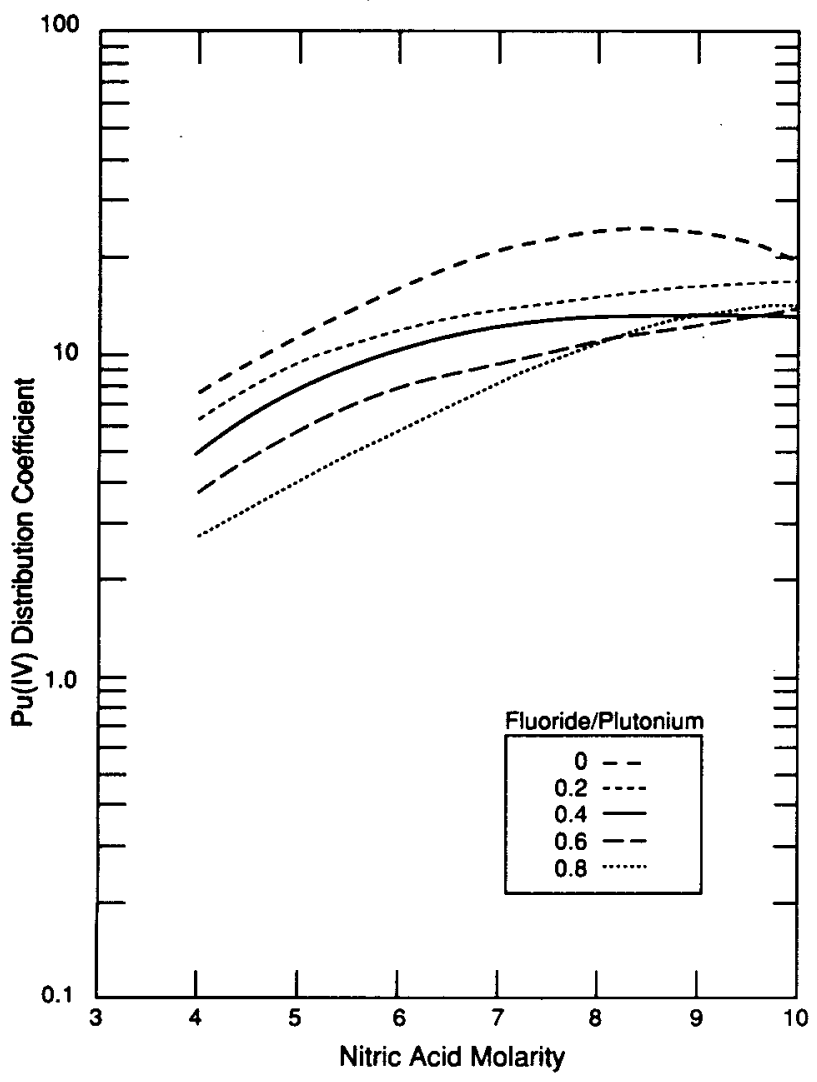

Fig. 3. Effect of nitric acid concentration and fluoride/Pu ratio on the distribution coefficient of $\mathrm{Pu}(\mathrm{IV})$ onto strong-base anion exchange resin $(\mathrm{F} / \mathrm{Pu}=0$ to $0.8, \mathrm{Pu}$ loading $=100$ grams per liter resin, dynamic contact period $=15$ minutes).

Figure 4 shows the distribution coefficient of $\mathrm{Pu}(\mathrm{IV})$ onto Lewatit ${ }^{T M}$ MP-500-FK strong-base anion exchange resin as a function of nitric acid concentration and oxalate-to-plutonium ratios of zero to 2 . Oxalate has relatively little effect on the distribution coefficients, which is in agreement with the relatively minor spectral changes caused by similar levels of oxalate.

\section{EFFECTS OF NITRIC ACID, FLUORIDE, AND OXALATE ON Pu(IV) SPECTRA}

Figures 5 through 34 illustrate the effects of varying concentrations of nitric acid and fluoride or oxalate

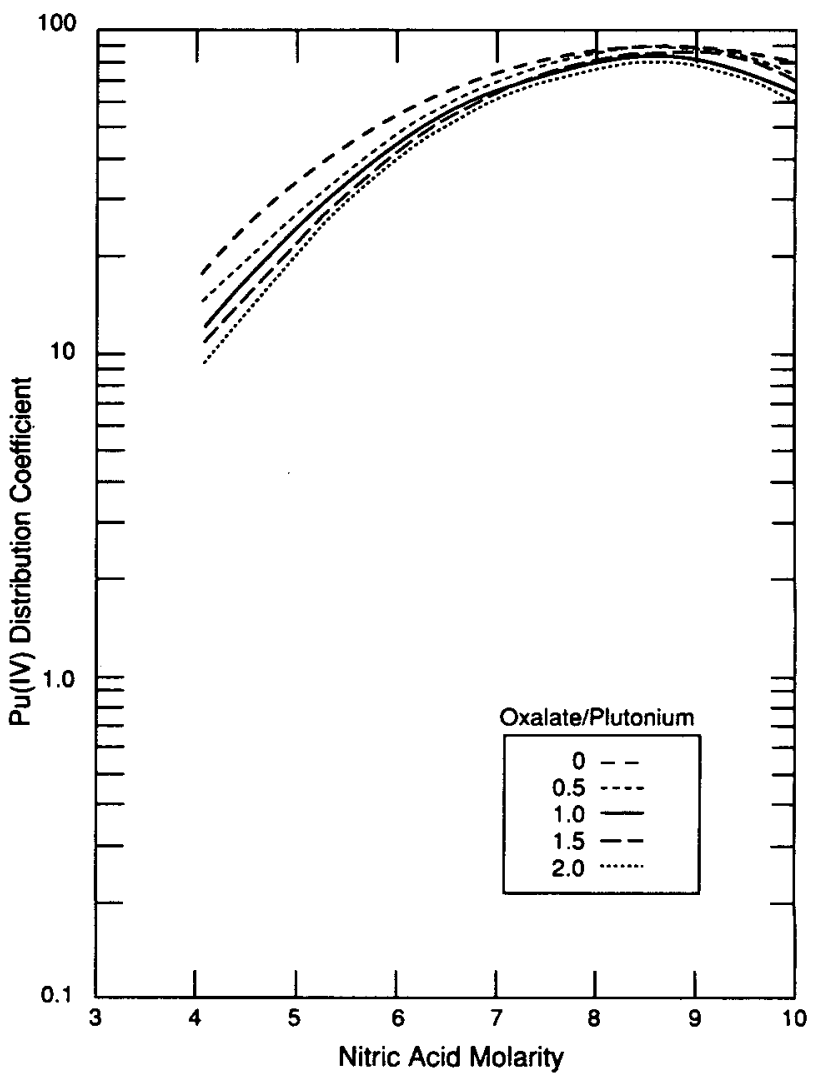

Fig. 4. Effect of nitric acid concentration and oxalate/Pu ratio on the distribution coefficient of $\mathrm{Pu}$ (IV) onto strong-base anion exchange resin (oxalate $/ \mathrm{Pu}=0$ to 2 , $\mathrm{Pu}$ loading $=20$ grams per liter resin, dynamic contact period $=15$ minutes).

on the spectra of $\mathrm{Pu}(\mathrm{IV})$. solutions. Figures 5 through 19 are for solutions with a plutonium concentration of 2 grams per liter. Figures 20 through 34 are for solutions with a plutonium concentration of 10 grams per liter. In the following discussion, wavelength values preceded by the symbol " $"$ are estimates of broad, poorly defined peaks that probably result from unresolved multiple peaks.

Because the quantities of fluoride or oxalate added to these two sets of solutions were identical, the fluoride/plutonium or oxalate/plutonium ratios were lower by a factor of 5 in the second set of solutions that contained a fivefold higher concentration of plutonium. 


\section{Effect of Varying Nitric Acid on Pu(IV) Spectra (2 Grams Pu per Liter)}

Figure 5 illustrates spectral changes of 2 grams per liter $\mathrm{Pu}(\mathrm{IV})$ solutions in the 400- to 880-nanometer region over the range of 4 to $10 \mathrm{M}$ nitric acid. As the nitric acid concentration increases, absorption peaks at 421,475 , 499 (hidden), $\sim 541,659,705,794$, and 851 nanometers decrease, whereas absorption peaks at 442, 490, 534, $553,608,649,684$, and 744 nanometers increase.

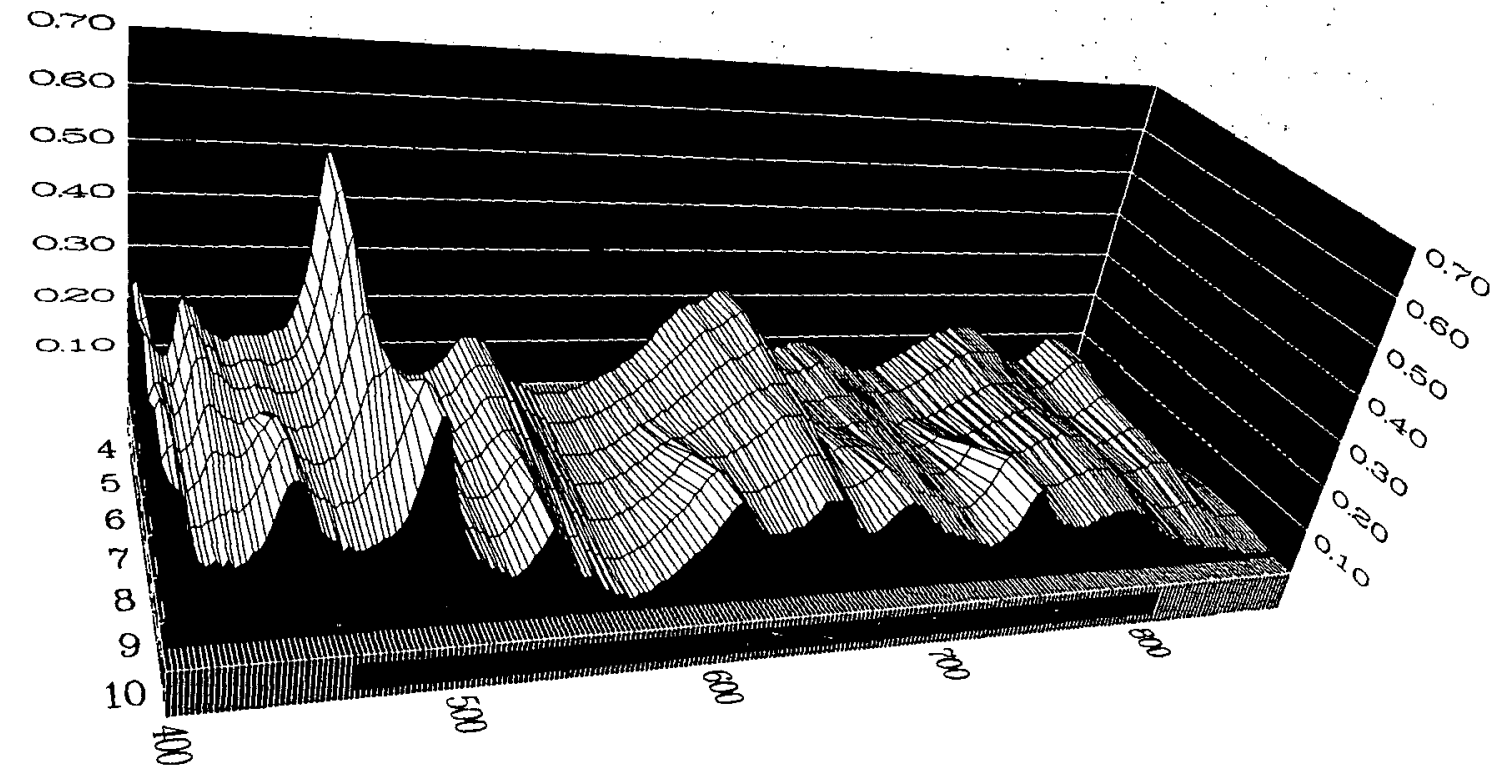

Fig. 5. Effect of nitric acid concentration on the spectra of plutonium nitrate solutions (2 grams Pu per liter, nitric acid $=4$, 5 , $6,7,8,9$, and $10 \mathrm{M}$ ).

\section{Effect of Varying Fluoride on Pu(IV) Spectra (2 Grams Pu per Liter, F/Pu = 0 to 4)}

Figure 6 shows the effect of increasing fluoride ( $\mathrm{F} / \mathrm{Pu}=0$ to 4 ) on the spectra of $\mathrm{Pu}(\mathrm{IV})$ in $4 M$ nitric acid. As the fluoride concentration increases, absorption peaks at $421,475,499, \sim 541,659,705, \sim 794$, and 851 nanometers decrease, whereas absorption peaks at 507, 568, and $\sim 726$ nanometers increase.

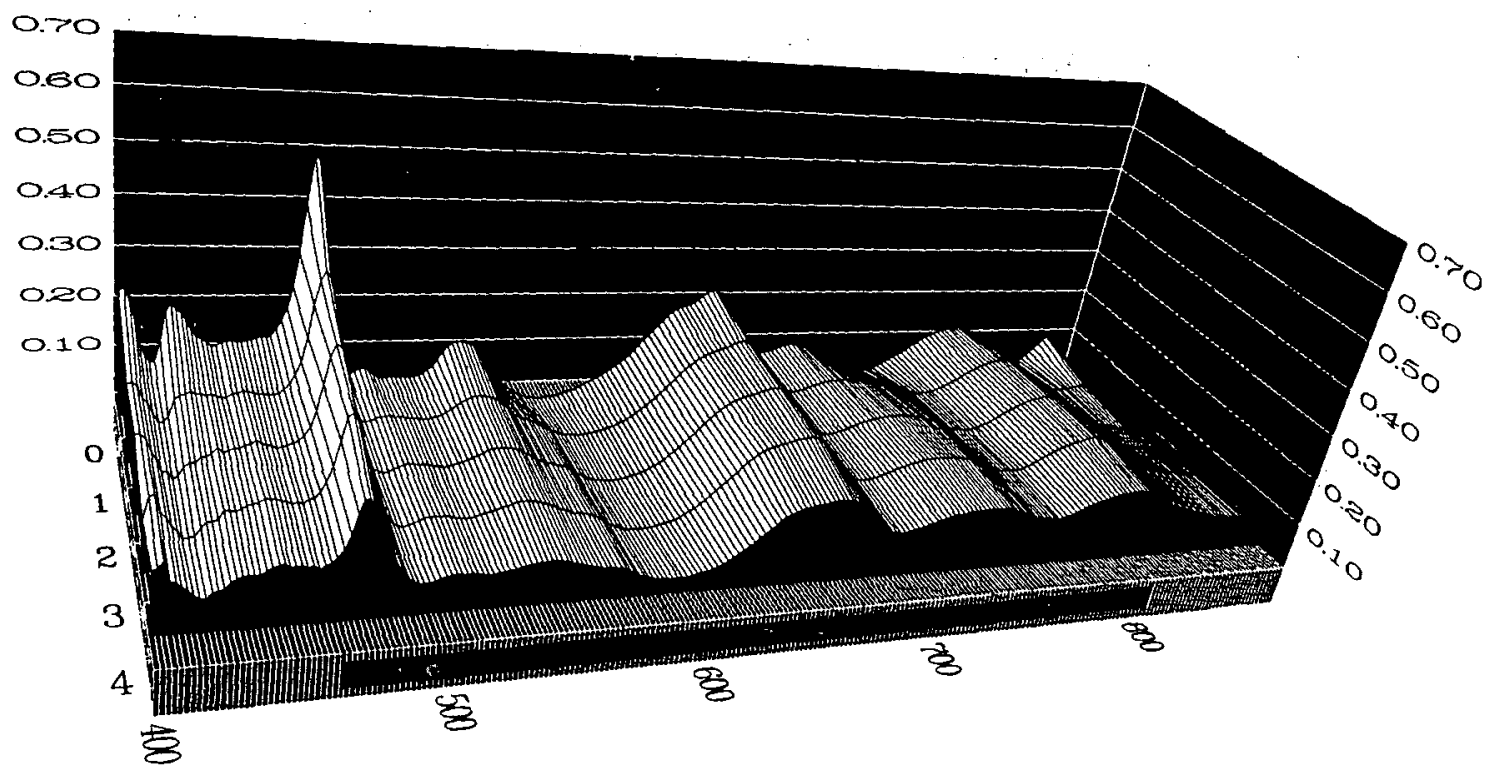

Fig. 6. Effect of fluoride on the spectra of plutonium nitrate solutions ( $4 M$ nitric acid, 2 grams $\mathrm{Pu}$ per liter, F/Pu $=0,1,2,3$, and 4). 
Figure 7 shows the effect of increasing fluoride ( $\mathrm{F} / \mathrm{Pu}=0$ to 4 ) on the spectra of $\mathrm{Pu}(\mathrm{IV})$ in $5 M$ nitric acid. As the fluoride concentration increases, absorption peaks at 421, 475, 499, 541, 659, 705, 794, and 851 nanometers decrease, whereas absorption peaks at 507, 568, and $\sim 726$ nanometers increase.

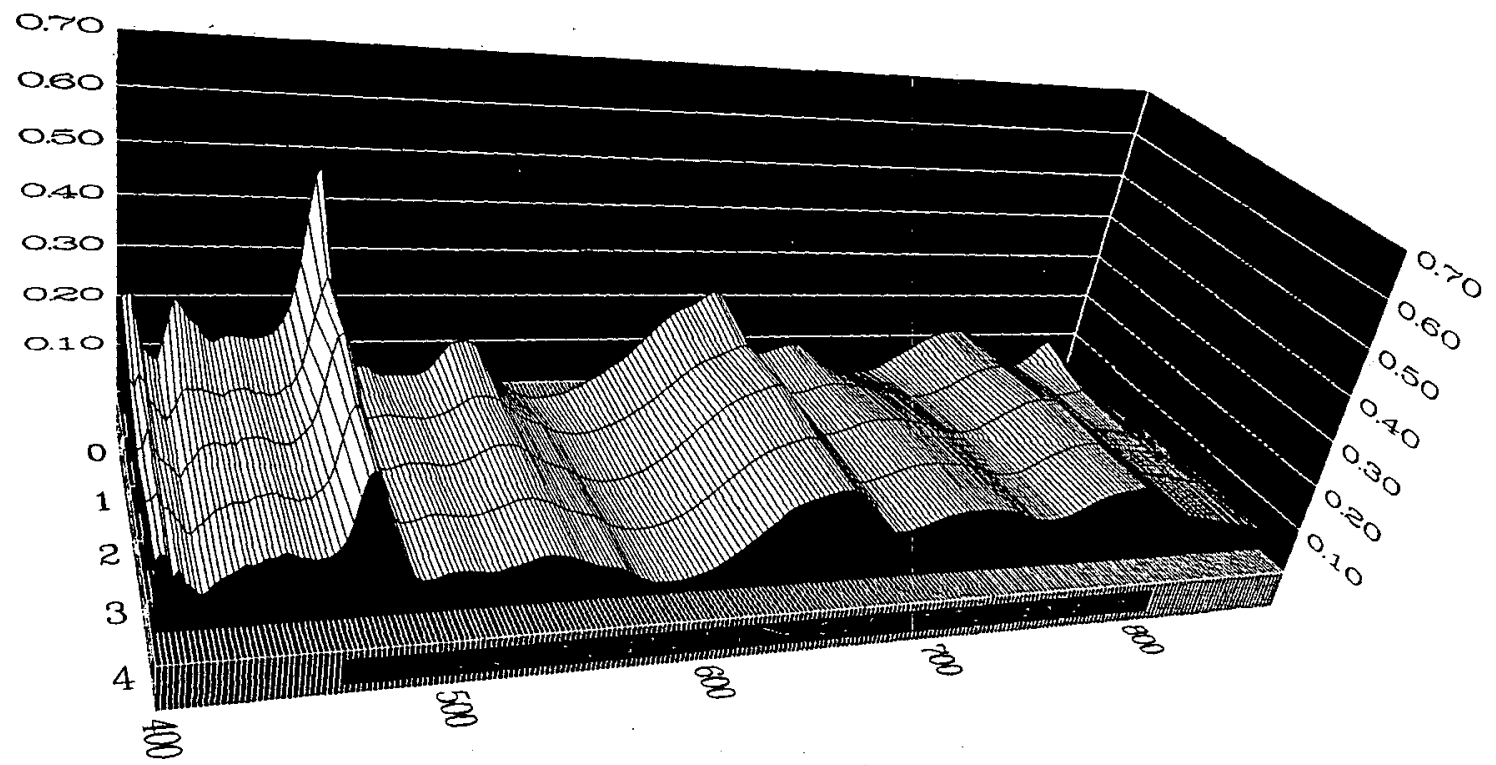

Fig. 7. Effect of fluoride on the spectra of plutonium nitrate solutions (5 $M$ nitric acid, 2 grams $\mathrm{Pu}$ per liter, F/Pu = 0, 1, 2, 3, and 4).

Figure 8 shows the effect of increasing fluoride ( $\mathrm{F} / \mathrm{Pu}=0$ to 4$)$ on the spectra of $\mathrm{Pu}(\mathrm{IV})$ in $6 \mathrm{M}$ nitric acid. As the fluoride concentration increases, absorption peaks at $421,475,499, \sim 540,659,705,794$, and 851 nanometers decrease, whereas absorption peaks at 507,568 , and $\sim 726$ nanometers increase. In addition to these changes, another peak at 442 nanometers, which is little affected by varying fluoride level, is beginning to appear.

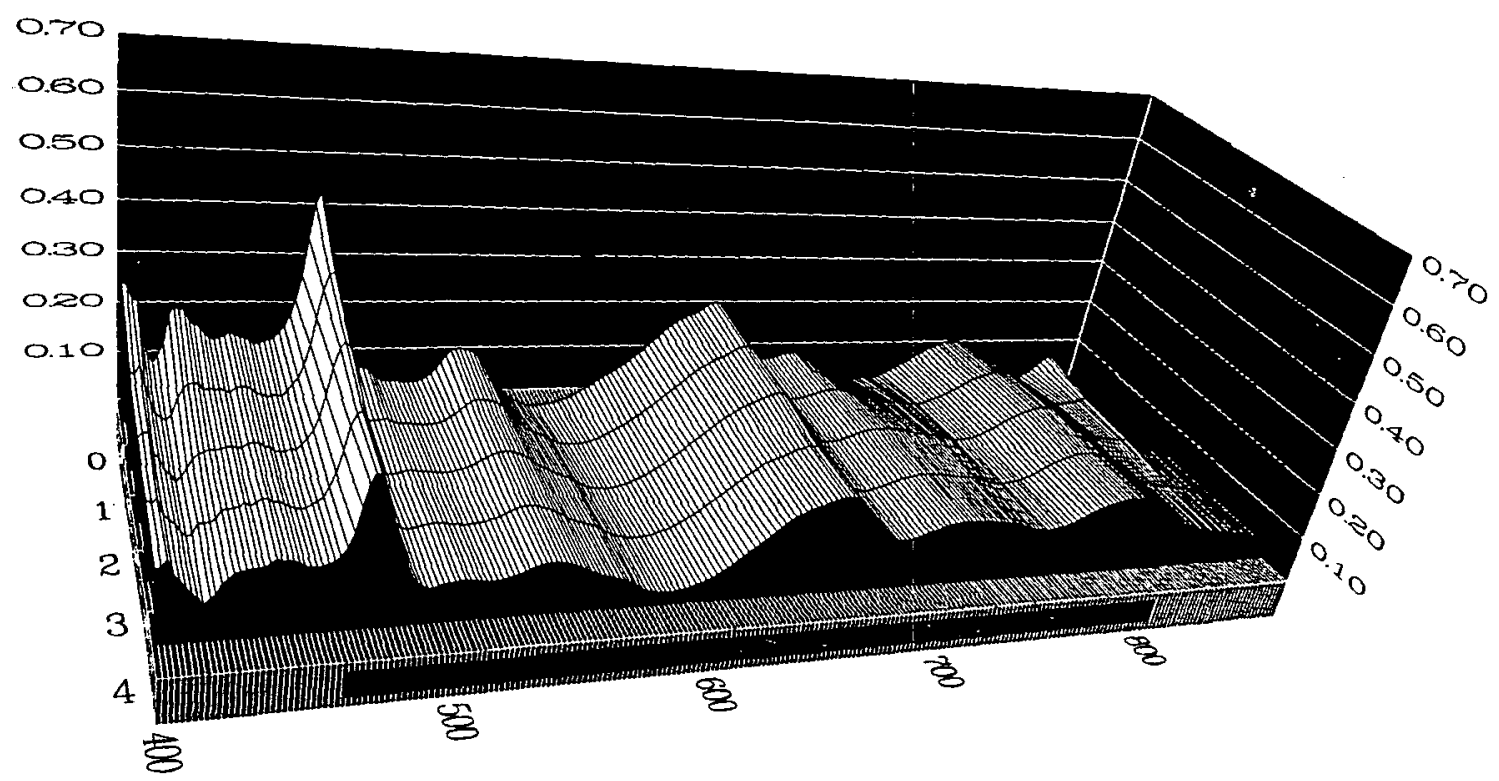

Fig. 8. Effect of fluoride on the spectra of plutonium nitrate solutions ( $6 M$ nitric acid, 2 grams $\mathrm{Pu}$ per liter, $\mathrm{F} / \mathrm{Pu}=0,1,2,3$, and 4). 
Figure 9 shows the effect of increasing fluoride ( $\mathrm{F} / \mathrm{Pu}=0$ to 4 ) on the spectra of $\mathrm{Pu}$ (IV) in $7 M$ nitric acid. As the fluoride concentration incrêases, absorption peaks at 421, 476, 499, $\sim 540,610,659,705,794$, and 851 nanometers decrease, whereas absorption peaks at 507, 568, and $\sim 734$ nanometers increase. The 442-nanometer peak continues to grow, whereas the 499-nanometer peak has almost disappeared.

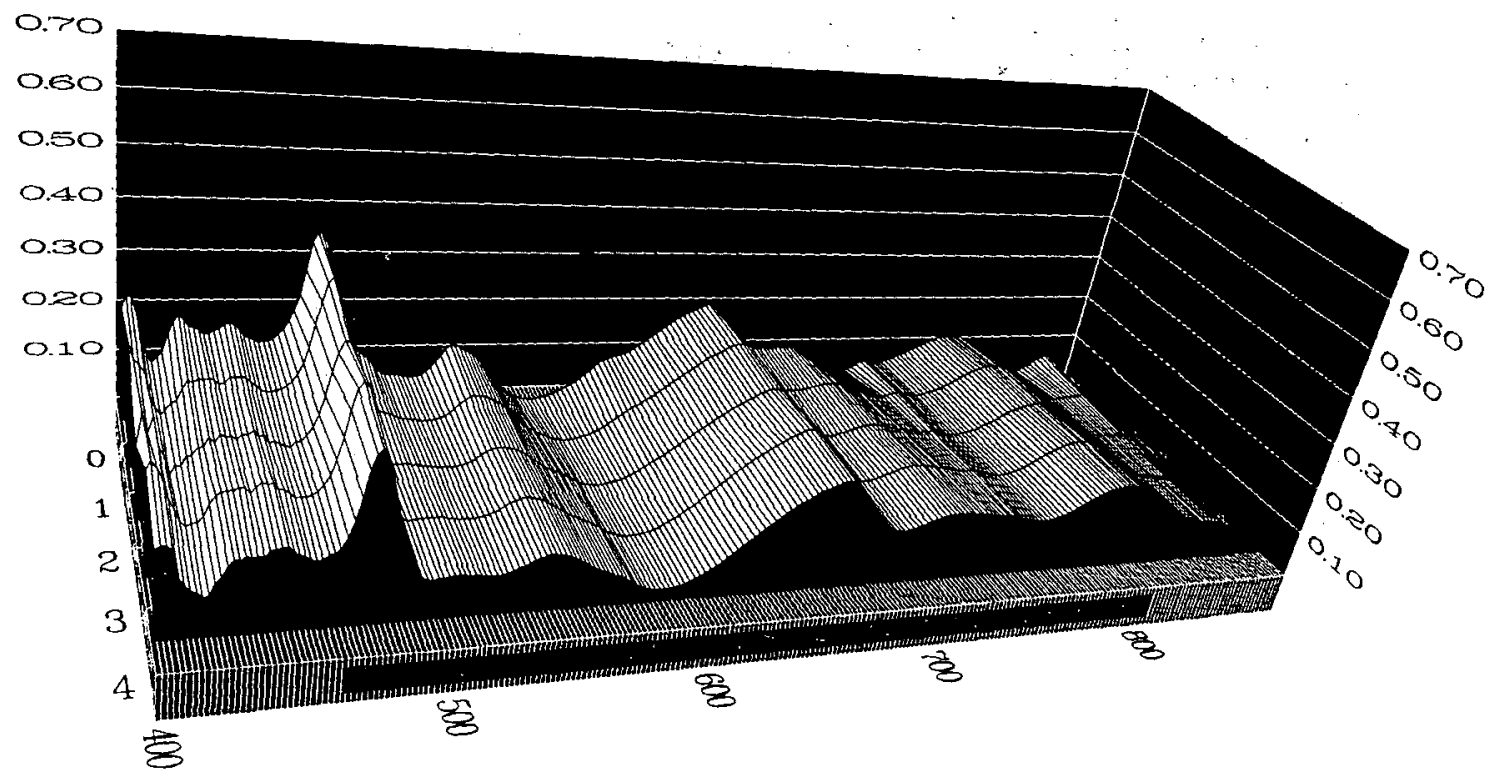

Fig. 9. Effect of fluoride on the spectra of plutonium nitrate solutions ( $7 \mathrm{M}$ nitric acid, 2 grams $\mathrm{Pu}$ per liter, F/Pu $=0,1,2,3$, and 4).

Figure 10 shows the effect of increasing fluoride $(\mathrm{F} / \mathrm{Pu}=0$ to 4$)$ on the spectra of $\mathrm{Pu}(\mathrm{IV})$ in $8 M$ nitric acid. As the fluoride concentration increases, absorption peaks at $421,442,534,608, \sim 655,684,744$, and 851 nanometers decrease, whereas absorption peaks at 502 (hidden), 568, 708, and 794 nanometers slightly increase. The combined $475+490$-nanometer peak at zero fluoride converts to a single 475-nanometer peak at the highest level of fluoride.

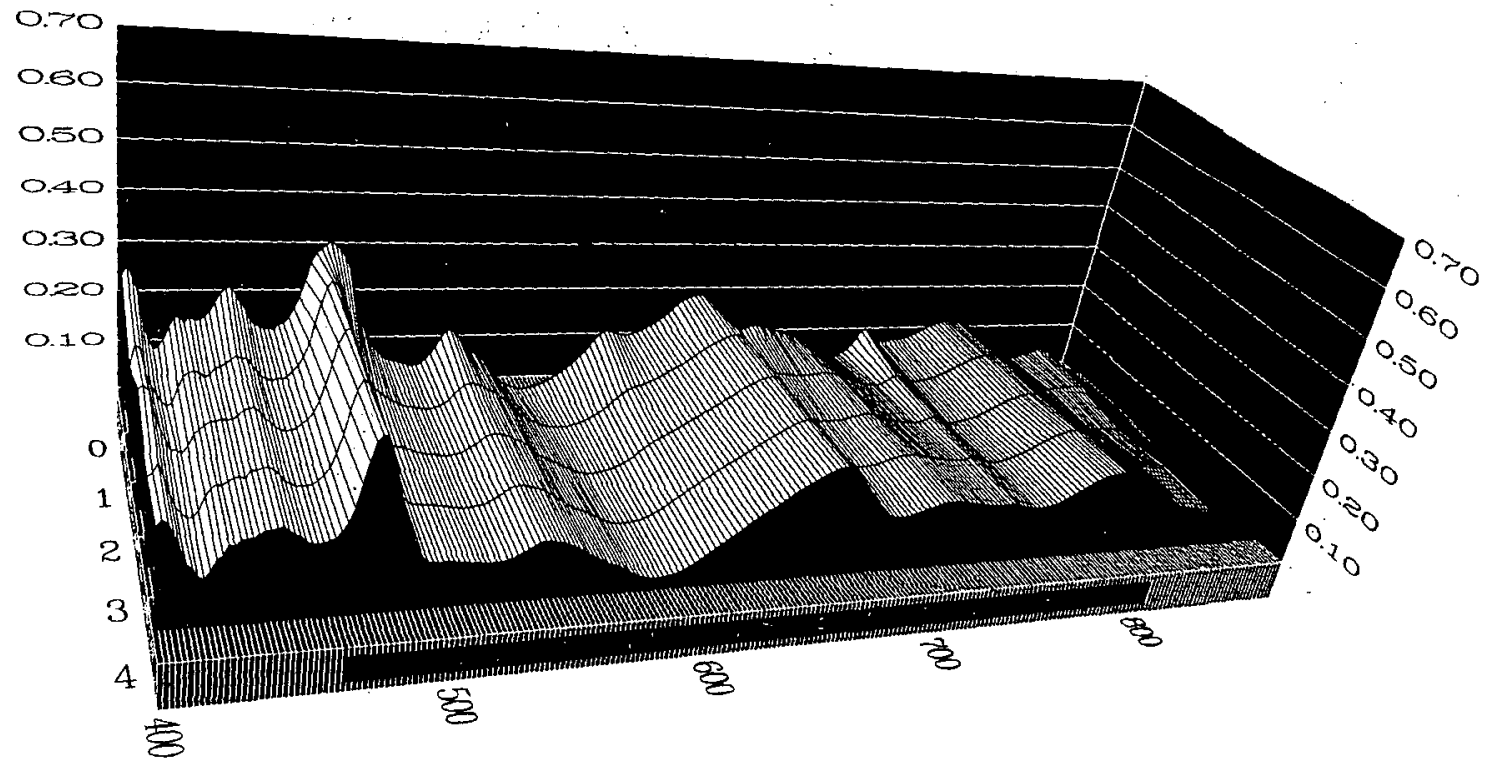

Fig. 10. Effect of fluoride on the spectra of plutonium nitrate solutions ( $8 \mathrm{M}$ nitric acid, 2 grams $\mathrm{Pu}$ per liter, F/Pu $=0,1,2,3$, and 4). 
Figure 11 shows the effect of increasing fluoride ( $\mathrm{F} / \mathrm{Pu}=0$ to 4 ) on the spectra of $\mathrm{Pu}(\mathrm{IV})$ in $9 \mathrm{M}$ nitric acid. As the fluoride concentration increases, absorption peaks at $421,442,490,534,608,650,684,744$, and 851 nanometers decrease, whereas absorption peaks at $475,655,708$, and 794 nanometers slightly increase.

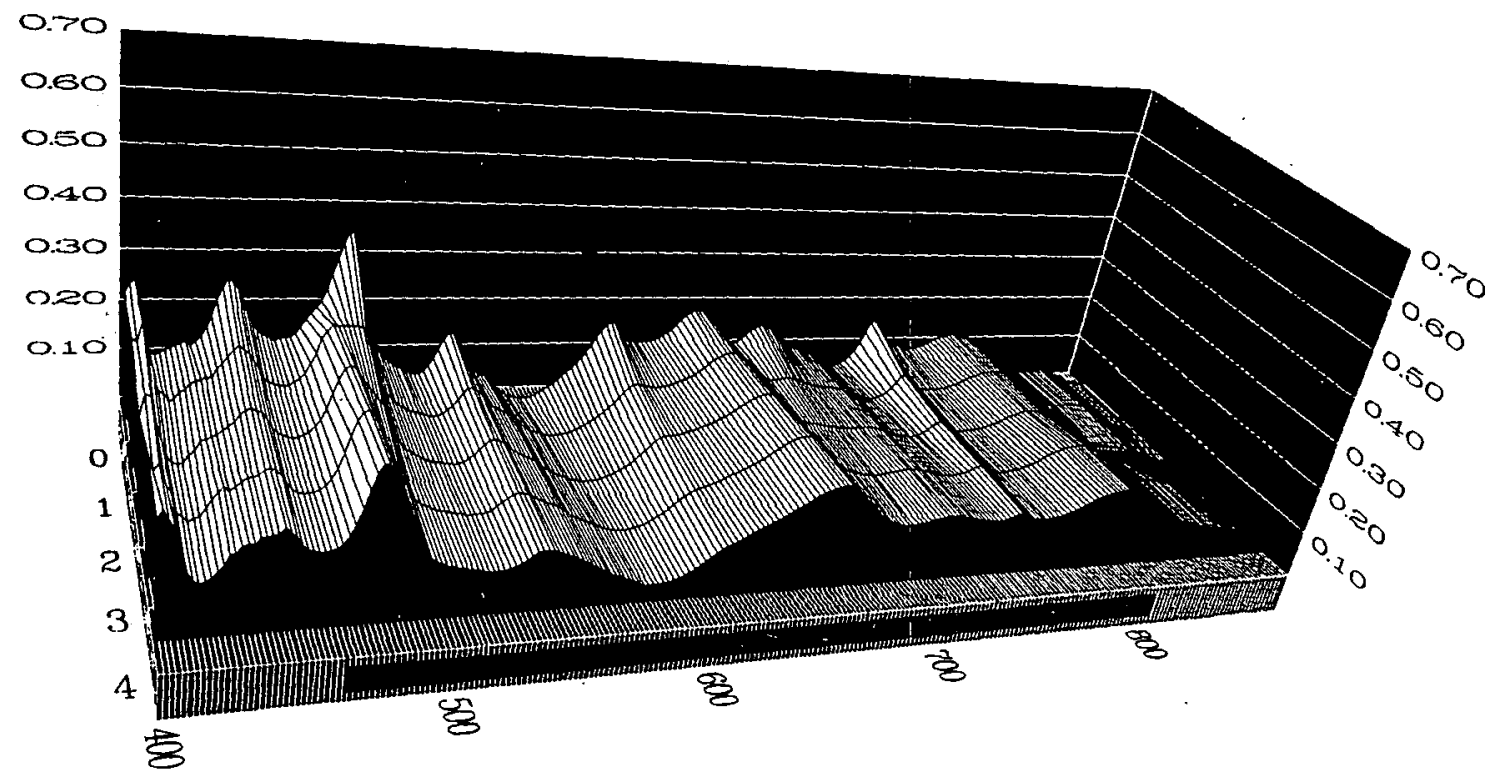

Fig. 11. Effect of fluoride on the spectra of plutonium nitrate solutions (9 $M$ nitric acid, 2 grams Pu per liter, F/Pu $=0,1,2,3$, and 4).

Figure 12 shows the effect of increasing fluoride (F/Pu $=0$ to 4 ) on the spectra of $\mathrm{Pu}(\mathrm{IV})$ in $10 \mathrm{M}$ nitric acid. As the fluoride concentration increases, absorption peaks at $420,442,490,534,608,650,684,744$, and 850 nanometers decrease, whereas absorption peaks at $475,655,708$, and 794 nanometers slightly increase. The 421- and 851-nanometer peaks are essentially absent in $10 \mathrm{M}$ nitric acid.

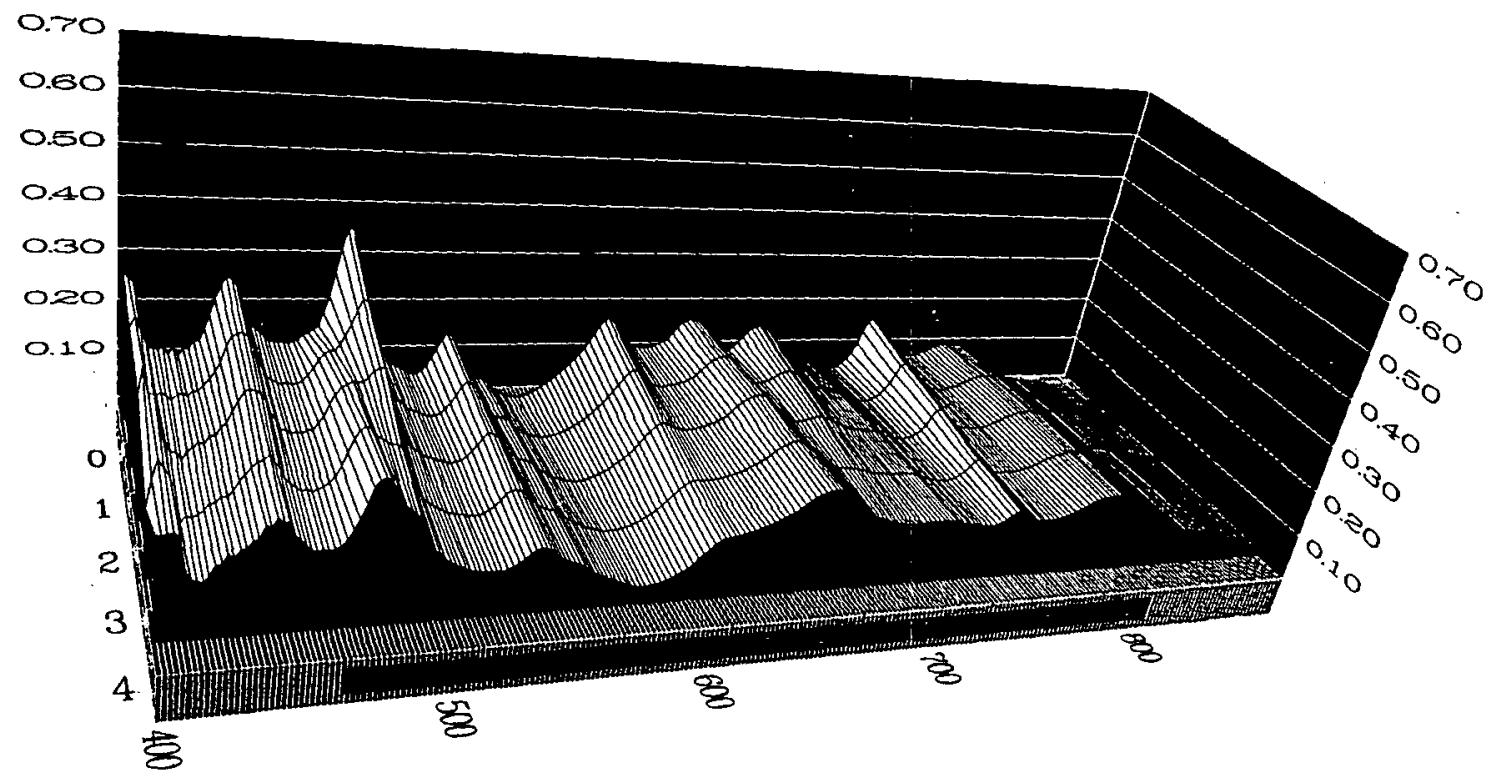

Fig. 12. Effect of fluoride on the spectra of plutonium nitrate solutions (10 $M$ nitric acid, 2 grams $\mathrm{Pu}$ per liter, $\mathrm{F} / \mathrm{Pu}=0,1,2$, 3 , and 4). 


\section{Effect of Varying Oxalate on Pu(IV) Spectra (2 Grams Pu per Liter, Oxalate/Pu = 0 to 2)}

Figure 13 shows the effect of increasing oxalate (oxalate/Pu $=0$ to 2 ) on the spectra of $\mathrm{Pu}(\mathrm{IV}$ ) in $4 M$ nitric acid. As the oxalate concentration increases, absorption peaks at $421,475,499$ (hidden), and 851 nanometers decrease, whereas the absorption peaks at 430,483 , and 649 nanometers increase.

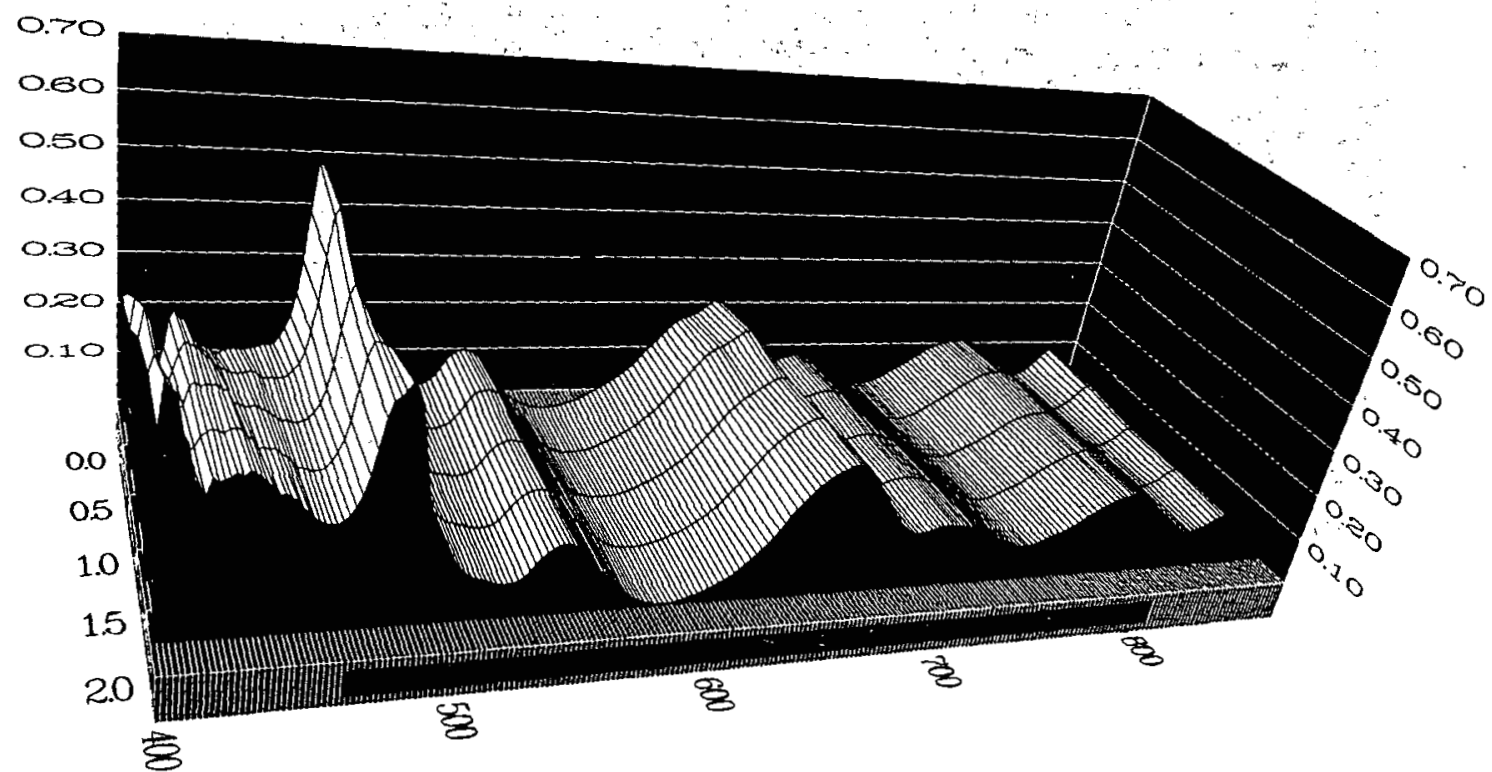

Fig. 13. Effect of oxalate on the spectra of plutonium nitrate solutions (4 $\mathrm{M}$ nitric acid, 2 grams $\mathrm{Pu}$ per liter, oxalate/Pu $=0$, $0.5,1,1.5$, and 2).

Figure 14 shows the effect of increasing oxalate (oxalate/ $\mathrm{Pu}=0$ to 2 ) on the spectra of $\mathrm{Pu}(\mathrm{IV}$ ) in $5 \mathrm{M}$ nitric acid. As the oxalate concentration increases, absorption peaks at $421,442,475,499$ (hidden), and 851 nanometers decrease, whereas the absorption peaks at 430 and 483 nanometers increase slightly.

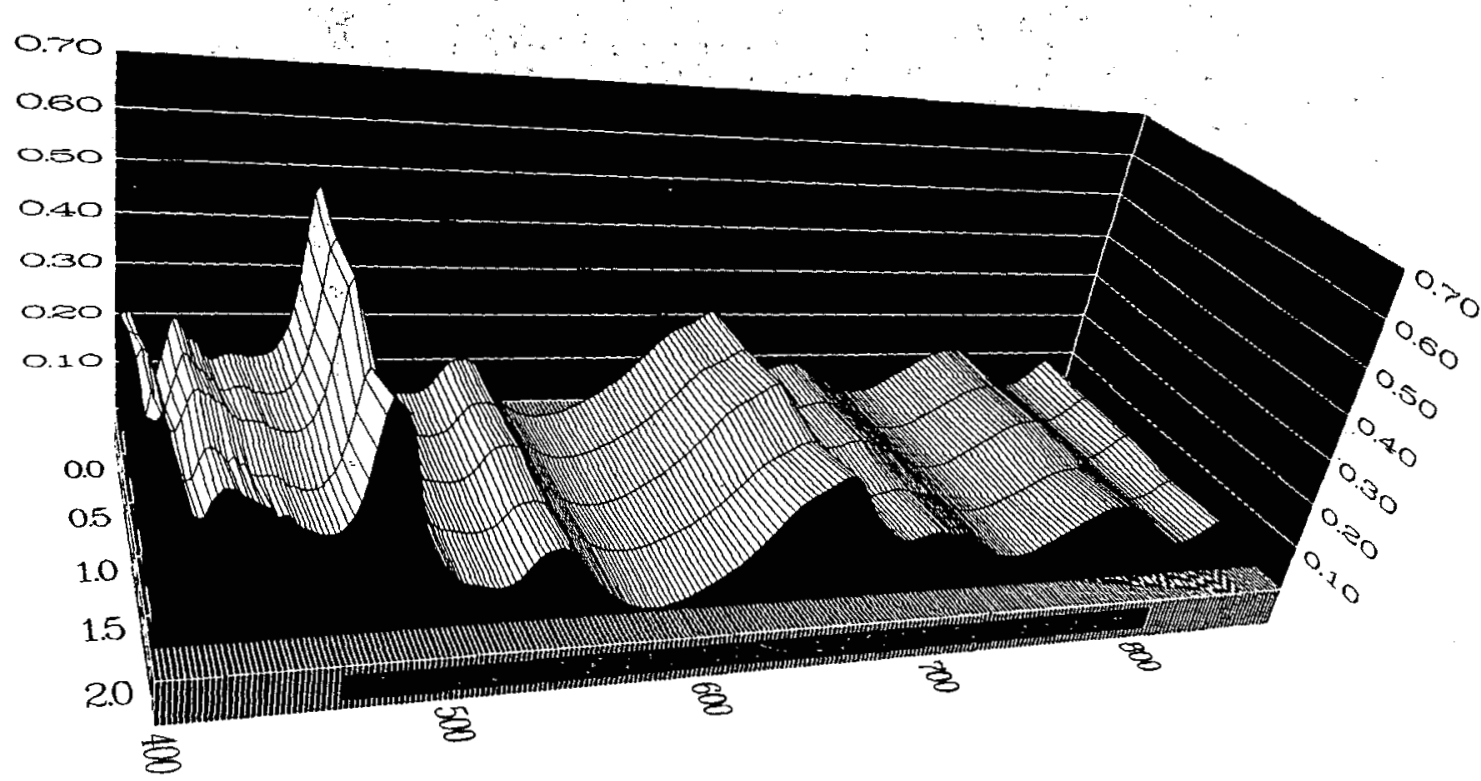

Fig. 14. Effect of oxalate on the spectra of plutonium nitrate solutions ( $5 \mathrm{M}$ nitric acid, 2 grams $\mathrm{Pu}$ per liter, oxalate/Pu $=0$, $0.5,1,1.5$, and 2). 
Figure 15 shows the effect of increasing oxalate (oxalate/ $\mathrm{Pu}=0$ to 2 ) on the spectra of $\mathrm{Pu}(\mathrm{IV})$ in $6 \mathrm{M}$ nitric acid. As the oxalate concentration increases, absorption peaks at 442,475 , and 499 (hidden) nanometers decrease, whereas the 483-nanometer absorption peak increases slightly.

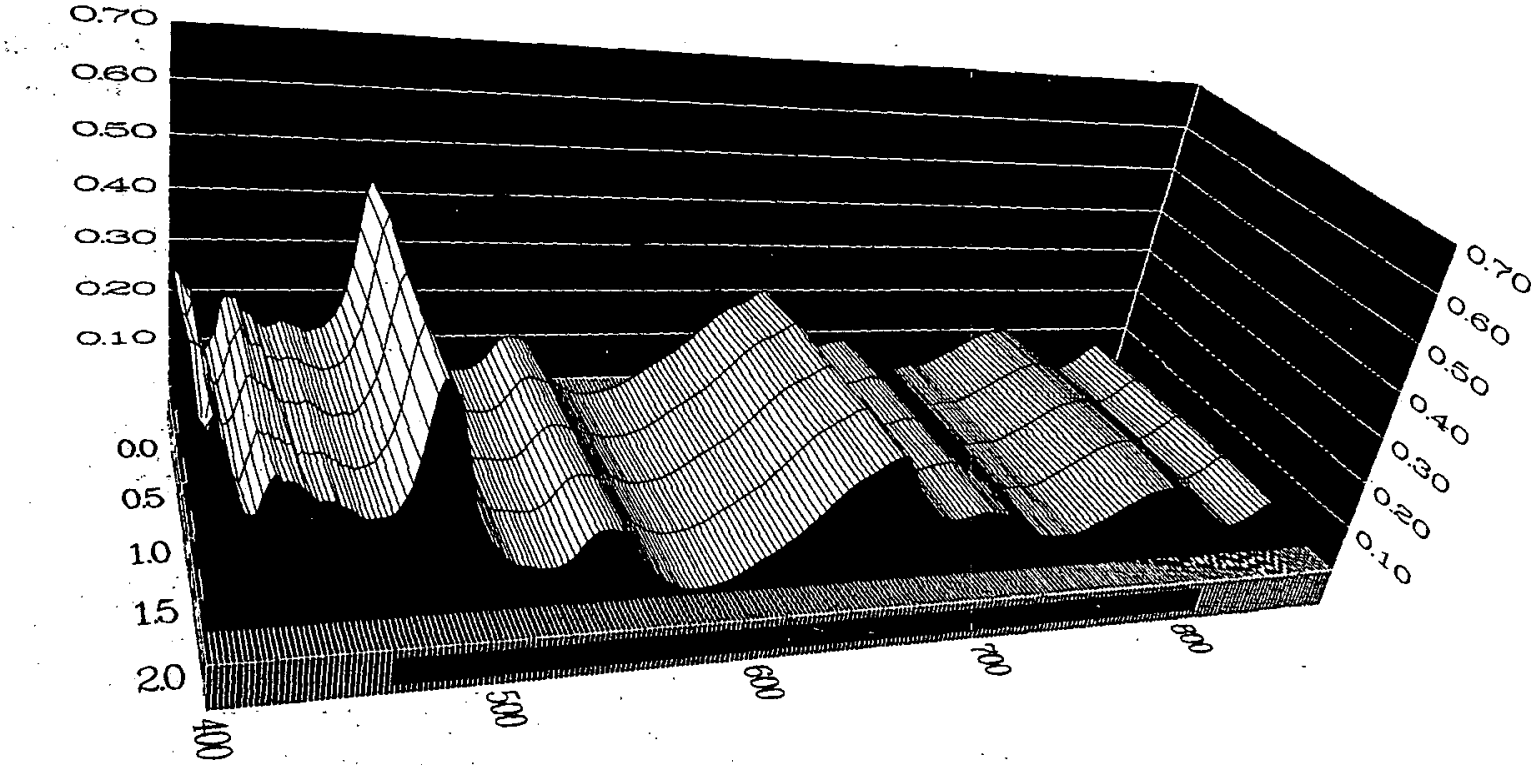

Fig. 15. Effect of oxalate on the spectra of plutonium nitrate solutions ( $6 M$ nitric acid, 2 grams $\mathrm{Pu}$ per liter, oxalate/Pu $=0$, $0.5,1,1.5$, and 2 ).

Figure 16 shows the effect of increasing oxalate (oxalate/Pu $=0$ to 2) on the spectra of $\mathrm{Pu}(\mathrm{IV}$ ) in $7 \mathrm{M}$ nitric acid. As the oxalate concentration increases, an absorption peak at 442 nanometers decreases, whereas the 483-nanometer absorption peak increases slightly.

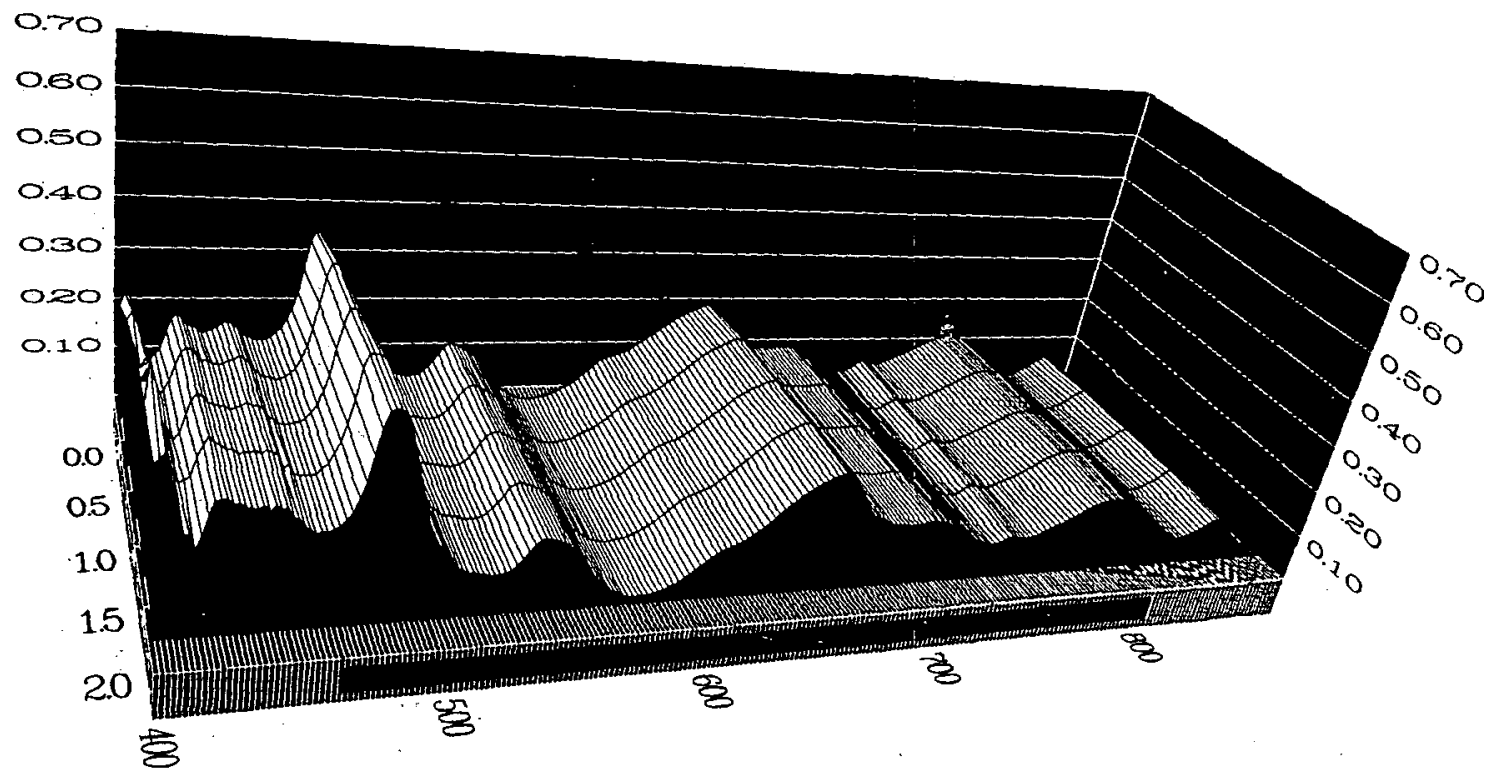

Fig. 16. Effect of oxalate on the spectra of plutonium nitrate solutions ( $7 M$ nitric acid, 2 grams $\mathrm{Pu}$ per liter, oxalate/Pu $=0$, $0.5,1,1.5$, and 2 ). 
Figure 17 shows the effect of increasing oxalate (oxalate/Pu $=0$ to 2) on the spectra of $\mathrm{Pu}(\mathrm{IV})$ in $8 M$ nitric acid. As the oxalate concentration increases, essentially no spectral changes occur. -

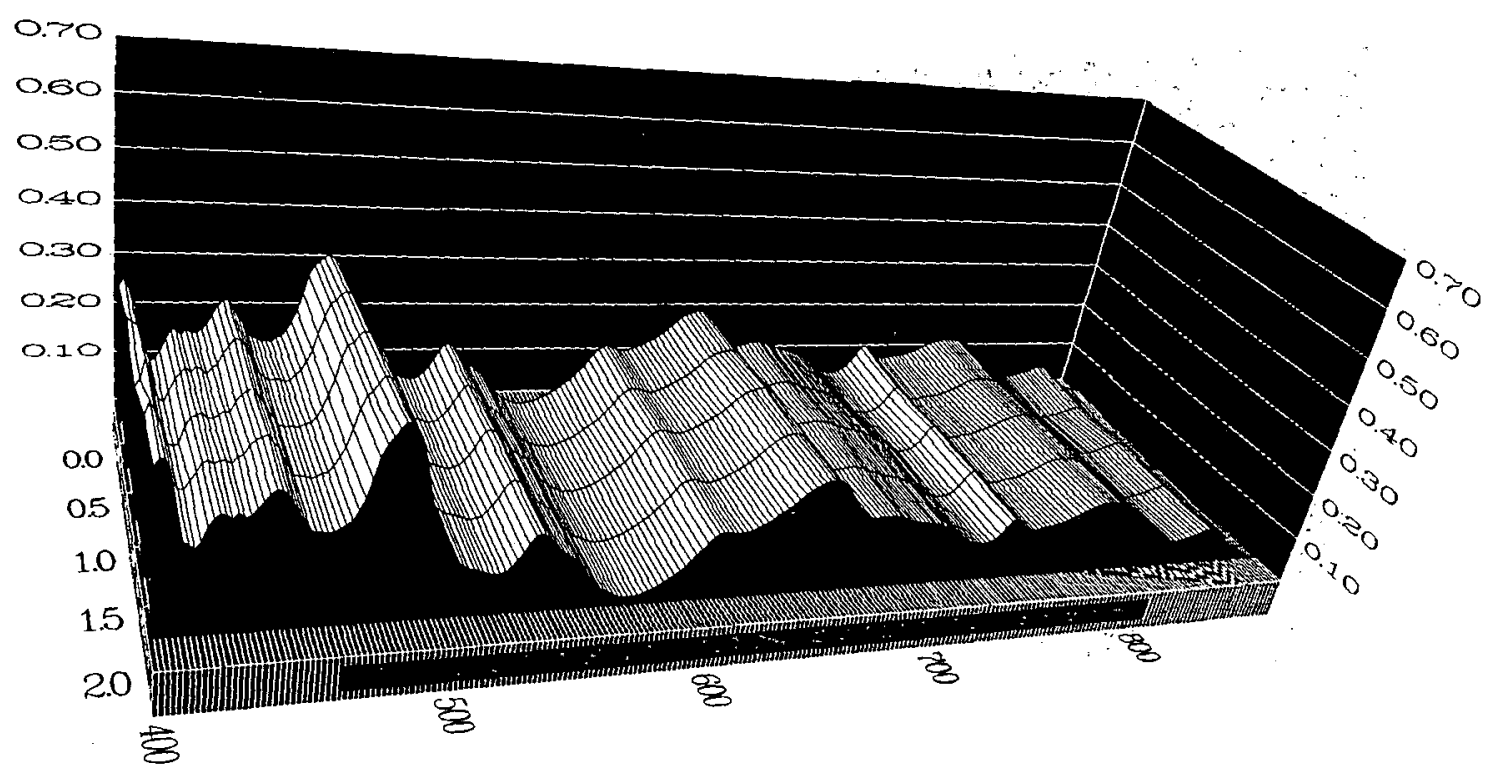

Fig. 17. Effect of oxalate on the spectra of plutonium nitrate solutions ( $8 M$ nitric acid, 2 grams $\mathrm{Pu}$ per liter, oxalate/Pu $=0$, $0.5,1,1.5$, and 2 ).

Figure 18 shows the effect of increasing oxalate (oxalate/Pu $=0$ to 2) on the spectra of $\mathrm{Pu}(\mathrm{IV})$ in $9 M$ nitric acid. As the oxalate concentration increases, essentially no spectral changes occur.

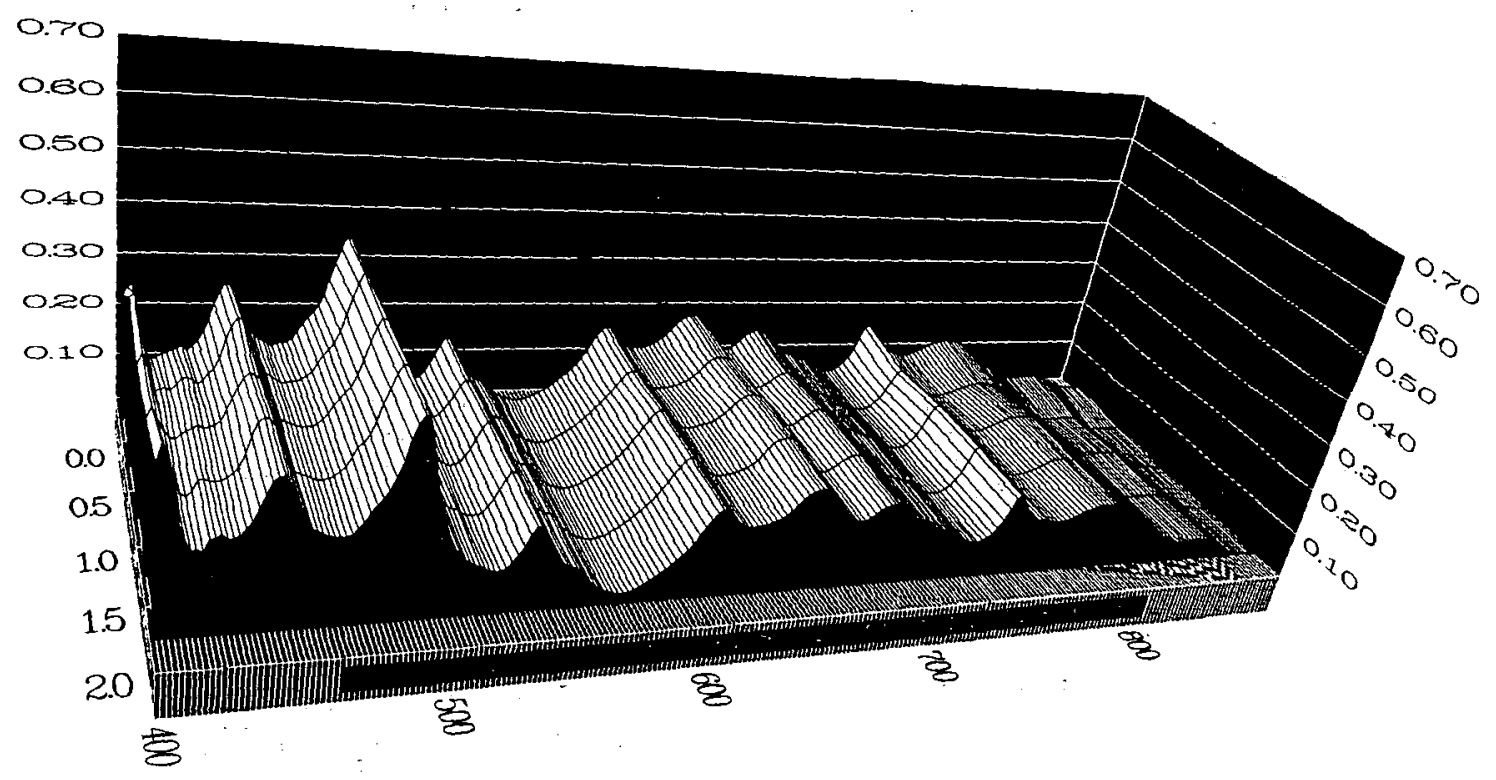

Fig. 18. Effect of oxalate on the spectra of plutonium nitrate solutions (9 $M$ nitric acid, 2 grams Pu per liter, oxalate/Pu $=0$, $0.5,1,1.5$, and 2 ). 
Figure 19 shows the effect of increasing oxalate (oxalate/Pu $=0$ to 2) on the spectra of $\mathrm{Pu}(\mathrm{IV}$ ) in $10 \mathrm{M}$ nitric acid. As the oxalate concentration increases, essentially no spectral changes occur.

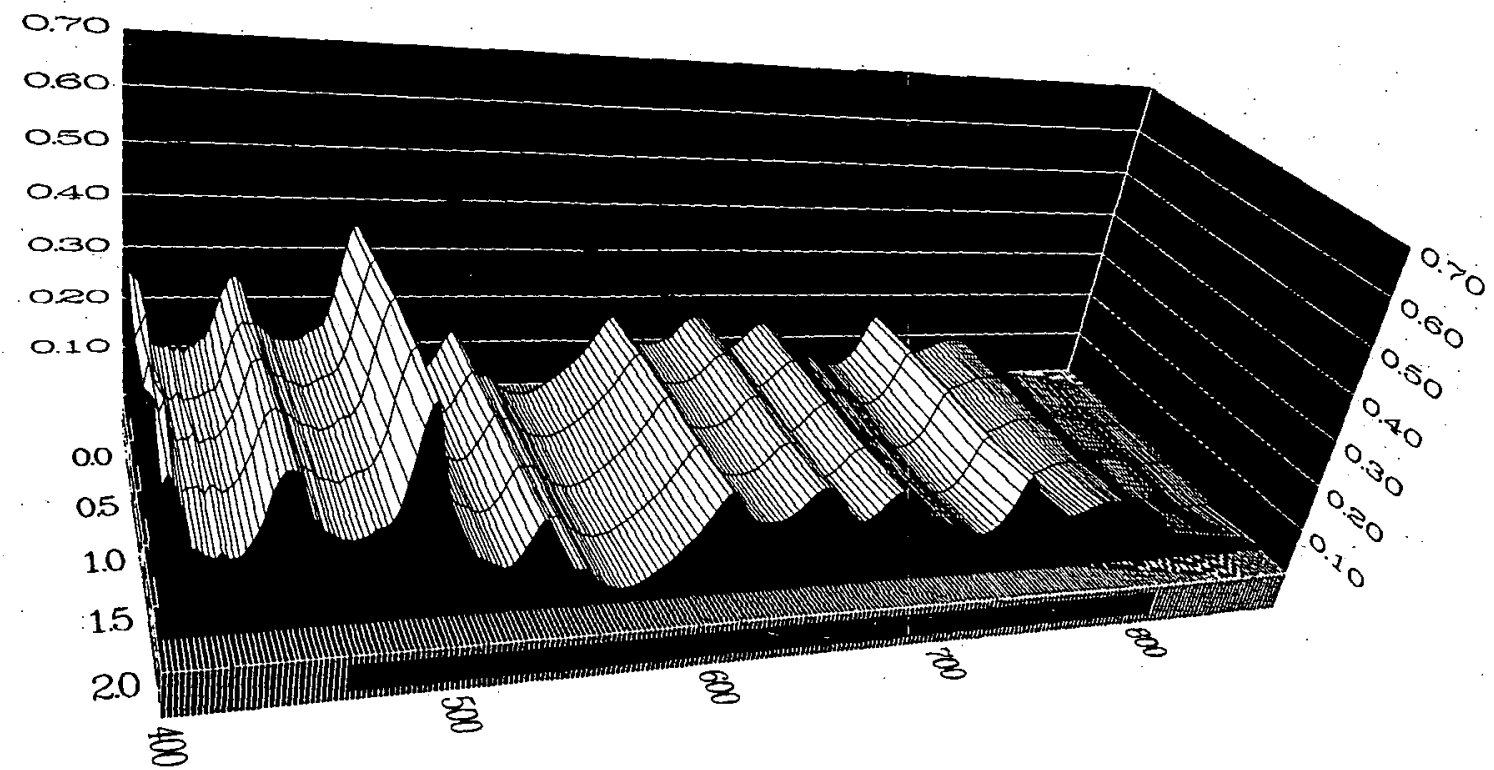

Fig. 19. Effect of oxalate on the spectra of plutonium nitrate solutions ( $10 \mathrm{M}$ nitric acid, 2 grams $\mathrm{Pu}$ per liter, oxalate/Pu $=0$, $0.5,1,1.5$, and 2$)$.

\section{Effect of Varying Nitric Acid on Pu(IV) Spectra (10 Grams Pu per Liter)}

Figure 20 illustrates spectral changes of 10 gram $\mathrm{Pu}$ (IV) per liter solutions in the 400 - to 880 -nanometer region over the range of 4 to $10 \mathrm{M}$ nitric acid. As the nitric acid concentration increases, absorption peaks at $421,475,499$ (hidden), $\sim 541,659,705, \sim 794$, and 851 nanometers decrease, whereas absorption peaks at 442 , $490,534,553,608,649,684$, and 744 nanometers increase.

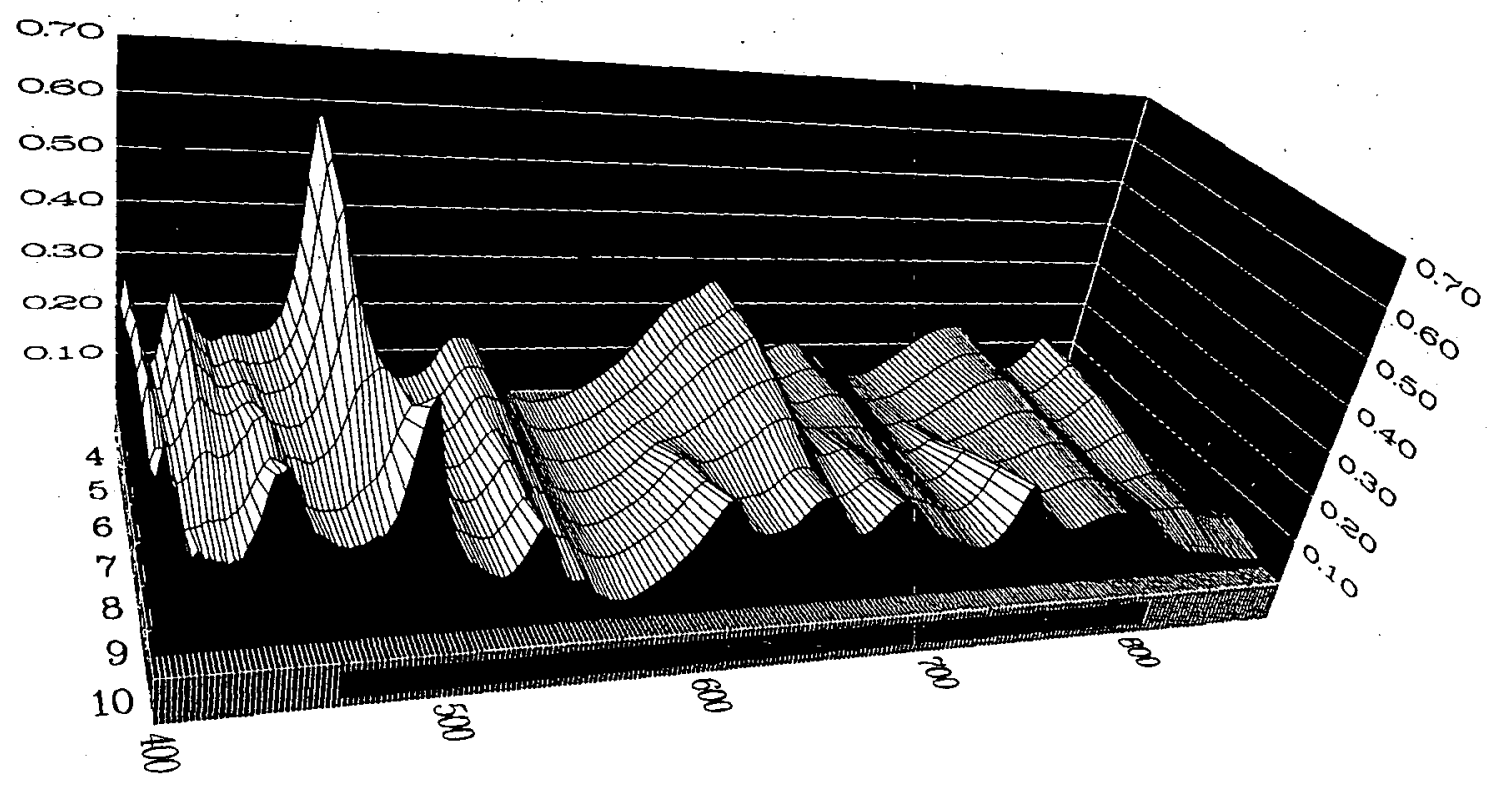

Fig. 20. Effect of nitric acid concentration on the spectra of plutonium nitrate solutions (10 grams Pu per liter, nitric acid $=4$, $5,6,7,8,9$, and $10 M$ ). 


\section{Effect of Varying Fluoride on Pu(IV) Spectra (10 Grams Pu per Liter, F/Pu $=0$ to 0.8 )}

Figure 21 shows the effect of increasing fluoride $(\mathrm{F} / \mathrm{Pu}=0$ to 0.8$)$ on the spectra of $\mathrm{Pu}(\mathrm{IV})$ in $4 M$ nitric acid. As the fluoride concentration increases, absorption peaks at 421, 475, 499 (hidden), $541,659,705,794$, and 851 nanometers decrease, whereas absorption peaks at 507, 568, and $\sim 726$ nanometers increase.

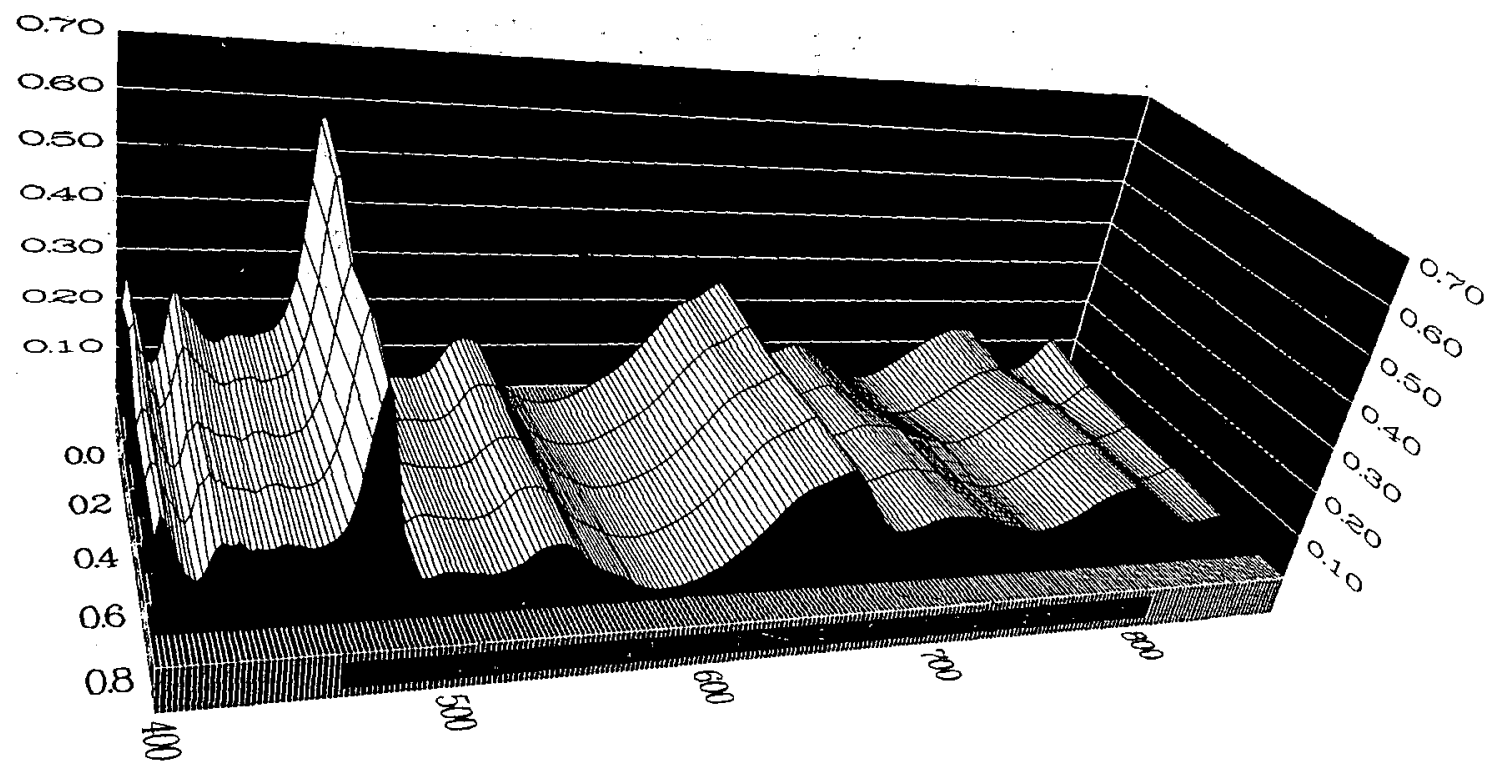

Fig. 21. Effect of fluoride on the spectra of plutonium nitrate solutions (4M nitric acid, 10 grams $\mathrm{Pu}$ per liter, $\mathrm{F} / \mathrm{Pu}=0,0.2$, $0.4,0.6$, and 0.8 ).

Figure 22 shows the effect of increasing fluoride $(\mathrm{F} / \mathrm{Pu}=0$ to 0.8$)$ on the spectra of $\mathrm{Pu}(\mathrm{IV})$ in $5 M$ nitric acid. As the fluoride concentration increases, absorption peaks at 421, 475, 499 (hidden), $541,659,705$, and 851 nanometers decrease, whereas absorption peaks at 507, 568, and $\sim 726$ nanometers increase.

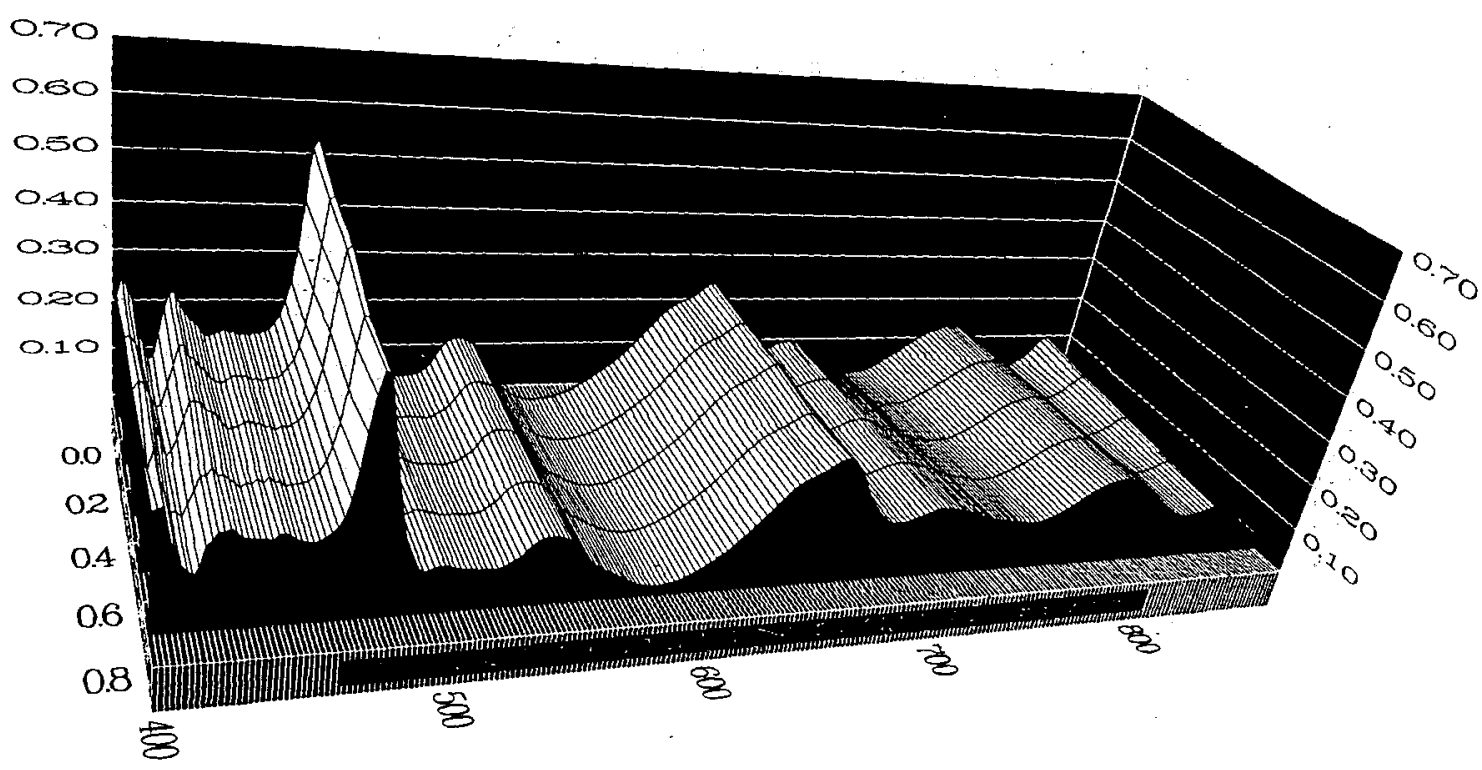

Fig. 22. Effect of fluoride on the spectra of plutonium nitrate solutions (5 $M$ nitric acid, 10 grams $\mathrm{Pu}$ per liter, $\mathrm{F} / \mathrm{Pu}=0,0.2$, $0.4,0.6$, and 0.8 ). 
Figure 23 shows the effect of increasing fluoride ( $\mathrm{F} / \mathrm{Pu}=0$ to 0.8 ) on the spectra of $\mathrm{Pu}(\mathrm{IV})$ in $6 \mathrm{M}$ nitric acid. As the fluoride concentration increases, absorption peaks at 421, 475, 499 (hidden), $541,659,705$, and 851 nanometers decrease, whereas absorption peaks at 507, 568, and $\sim 726$ nanometers increase.

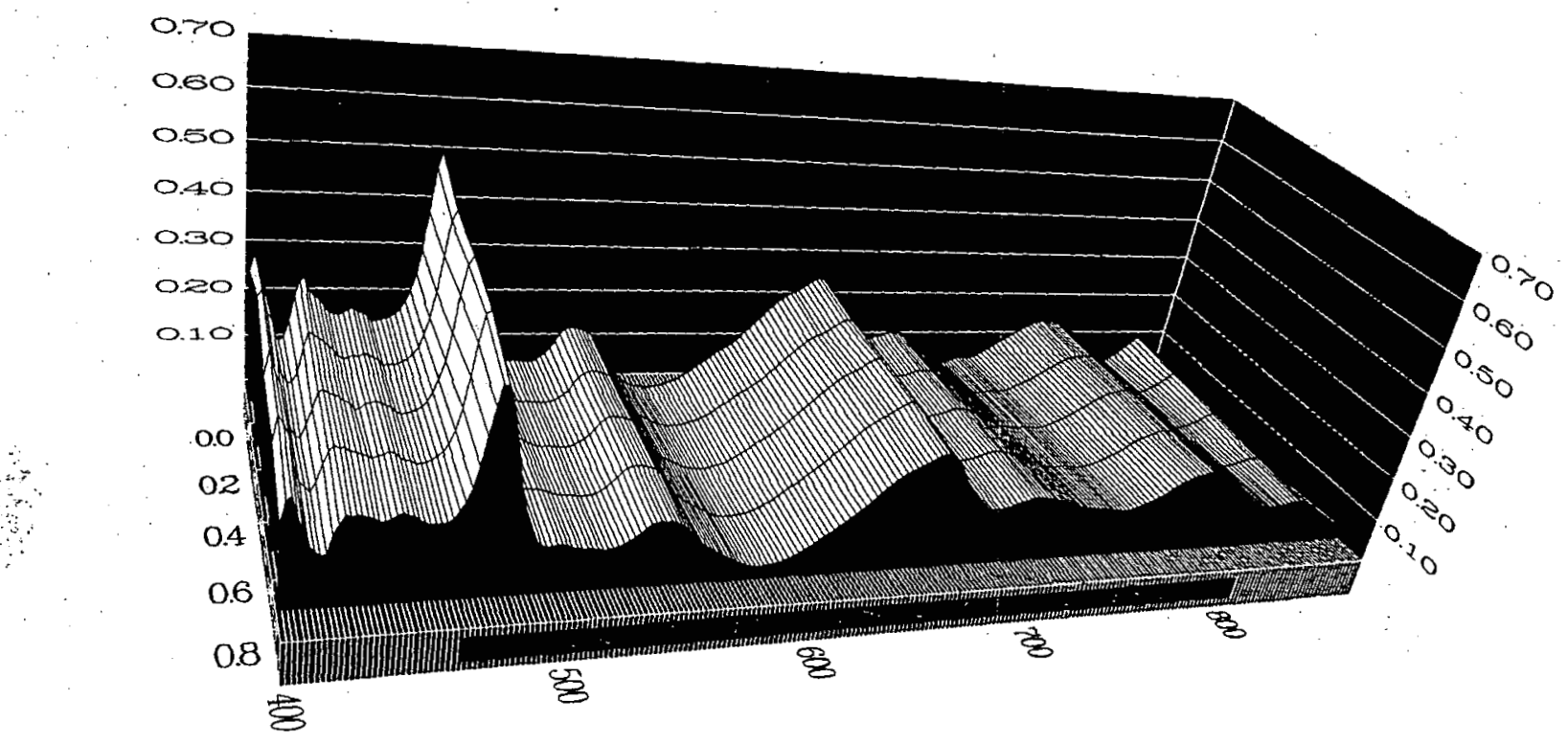

Fig. 23. Effect of fluoride on the spectra of plutonium nitrate solutions (6 M nitric acid, 10 grams Pu per liter, F/Pu $=0,0.2$, $0.4,0.6$, and 0.8 ).

Figure 24 shows the effect of increasing fluoride $(\mathrm{F} / \mathrm{Pu}=0$ to 0.8$)$ on the spectra of $\mathrm{Pu}(\mathrm{IV})$ in $7 \mathrm{M}$ nitric acid. As the fluoride concentration increases, absorption peaks at 421, 442, 475, 499 (hidden), $\sim 540,610,659$, $\sim 692,705,794$, and 851 nanometers decrease, whereas absorption peaks at 568 and $\sim 726$ nanometers increase.

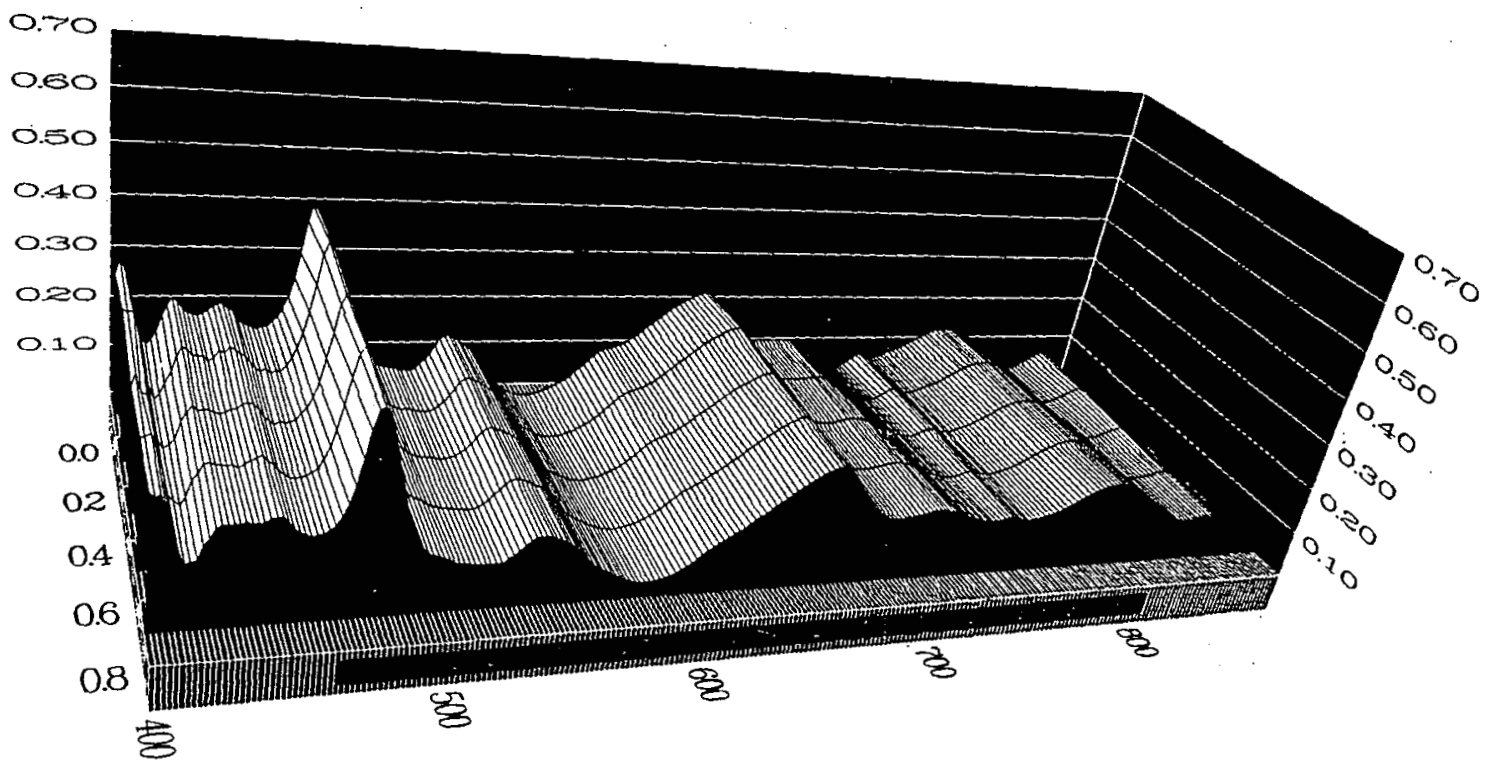

Fig. 24. Effect of fluoride on the spectra of plutonium nitrate solutions ( $7 \mathrm{M}$ nitric acid, 10 grams $\mathrm{Pu}$ per liter, F/Pu $=0,0.2$, $0.4,0.6$, and 0.8 ). 
Figure 25 shows the effect of increasing fluoride ( $\mathrm{F} / \mathrm{Pu}=0$ to 0.8 ) on the spectra of $\mathrm{Pu}(\mathrm{IV})$ in $8 \mathrm{M}$ nitric acid. As the fluoride concentration increases, absorption peaks at $421,442,483,534,608,653,684,743$, and 851 nanometers decrease, whereas the absorption peaks at 476,708 , and 792 nanometers increase.

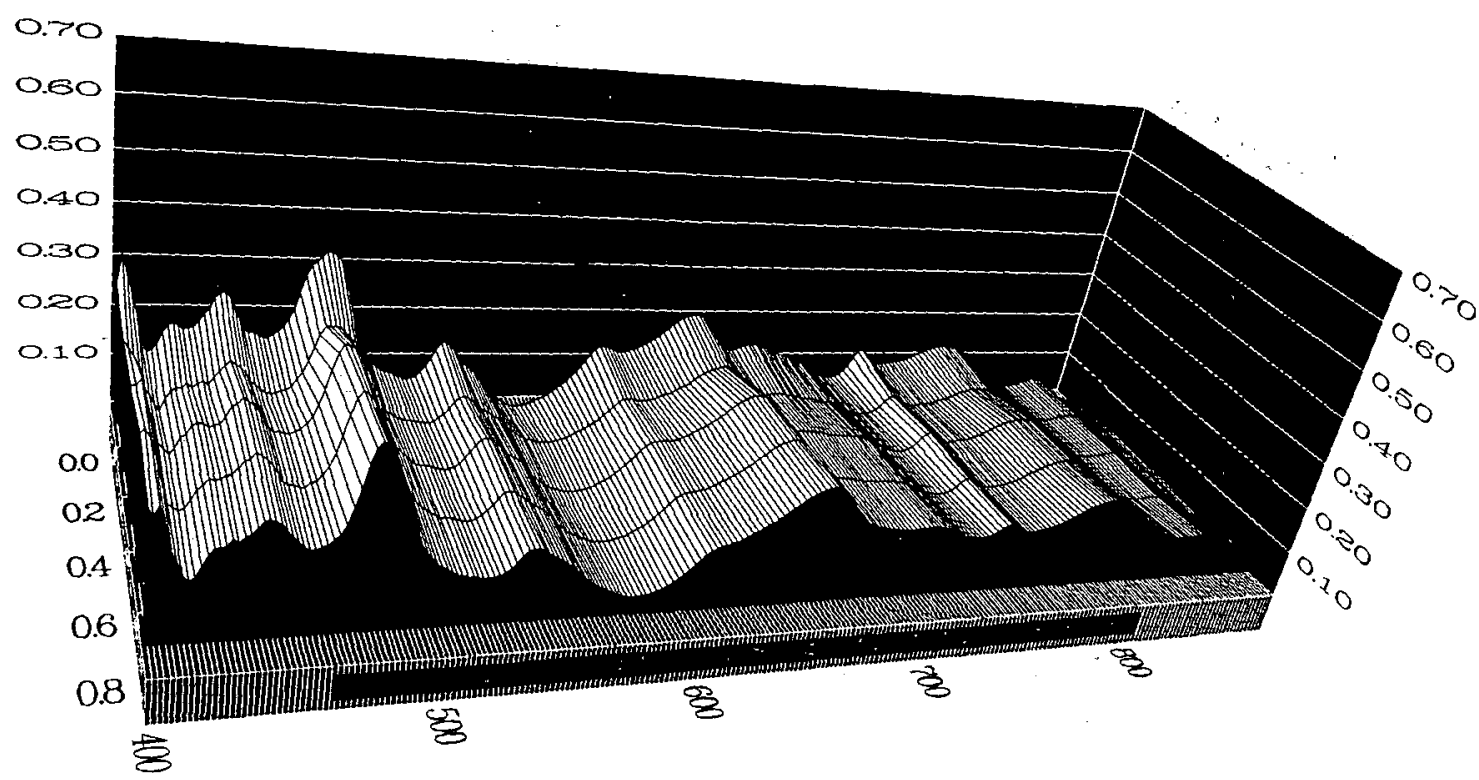

Fig. 25. Effect of fluoride on the spectra of plutonium nitrate solutions ( $8 \mathrm{M}$ nitric acid, 10 grams $\mathrm{Pu}$ per liter, $\mathrm{F} / \mathrm{Pu}=0,0.2$, $0.4,0.6$, and 0.8 ).

Figure 26 shows the effect of increasing fluoride (F/Pu $=0$ to 0.8 ) on the spectra of $\mathrm{Pu}(\mathrm{IV})$ in $9 \mathrm{M}$ nitric acid. As the fluoride concentration increases, absorption peaks at $442,489,534,608,684,749$, and 850 nanometers decrease, whereas absorption peaks at $476,653,707$, and 793 nanometers increase.

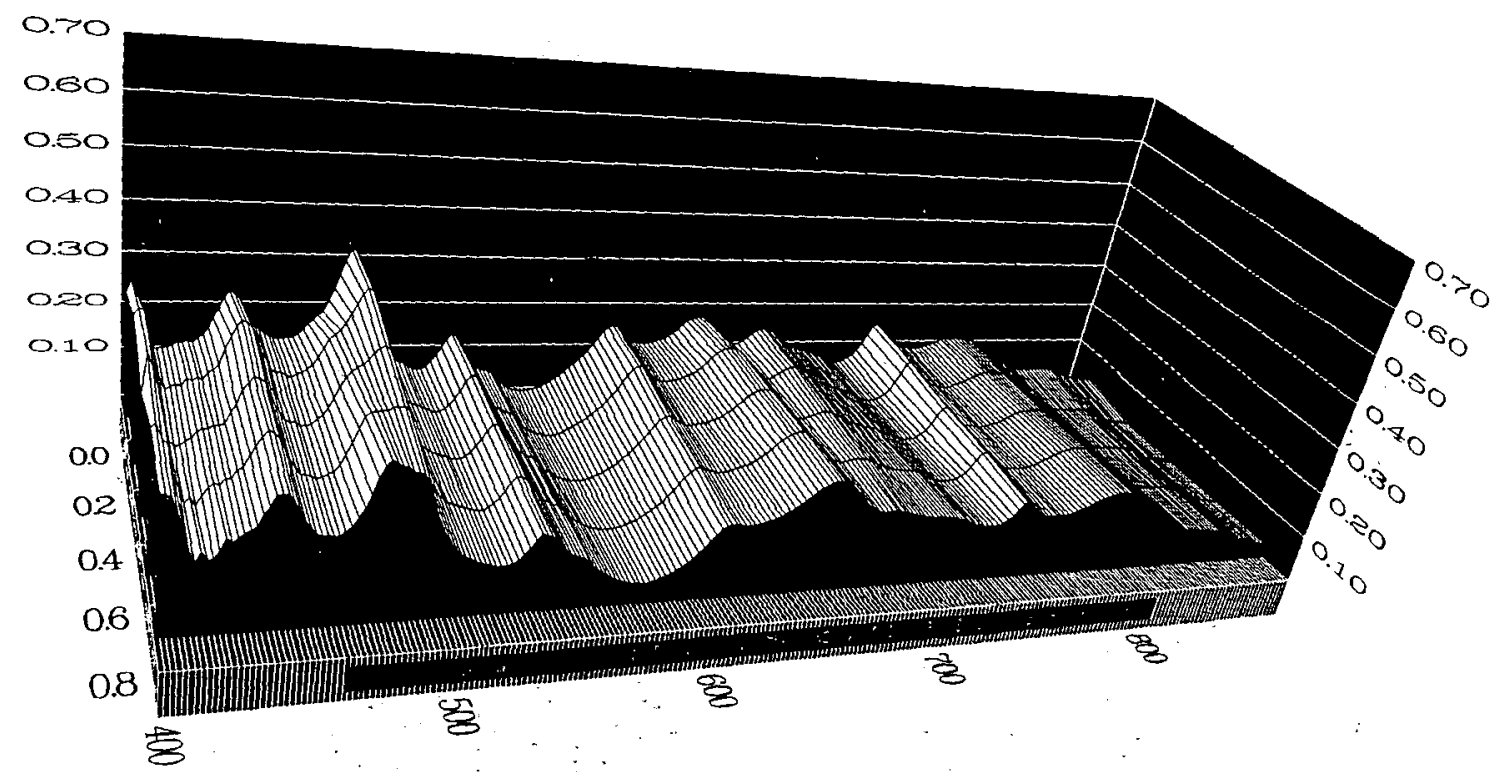

Fig. 26. Effect of fluoride on the spectra of plutonium nitrate solutions ( $9 \mathrm{M}$ nitric acid, 10 grams $\mathrm{Pu}$ per liter, $\mathrm{F} / \mathrm{Pu}=0,0.2$, $0.4,0.6$, and 0.8 ). 
Figure 27 shows the effect of increasing fluoride ( $\mathrm{F} / \mathrm{Pu}=0$ to 0.8 ) on the spectra of $\mathrm{Pu}(\mathrm{IV})$ in $10 \mathrm{M}$ nitric acid. As the fluoride concentration increases, absorption peaks at 442, 489,534,608,689, and 744 nanometers decrease, whereas absorption peaks at 476,653 , and 793 nanometers increase. The 421 - and 850-nanometer peaks are essentially absent in $10 \mathrm{M}$ nitric acid.

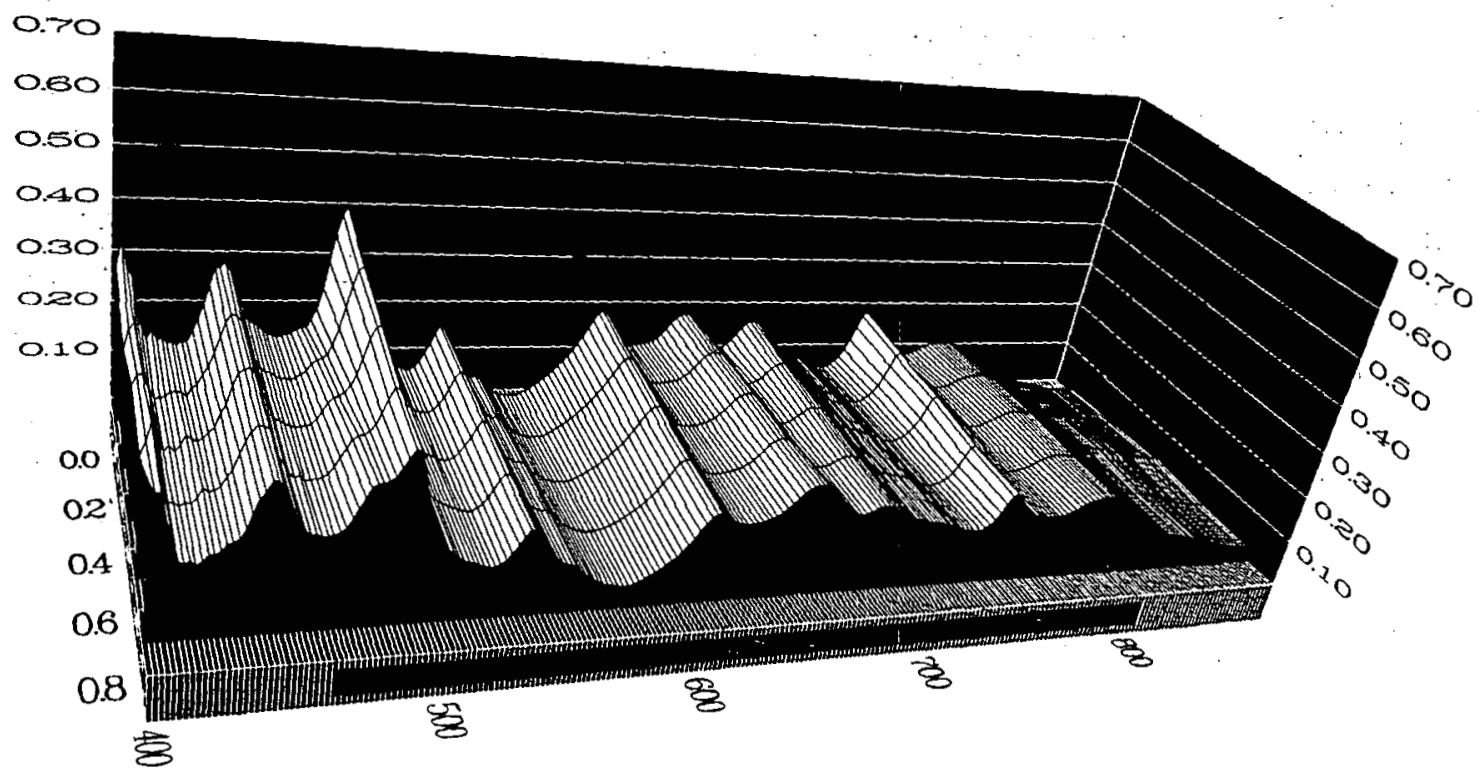

Fig. 27. Effect of fluoride on the spectra of plutonium nitrate solutions (10 $\mathrm{M}$ nitric acid, 10 grams $\mathrm{Pu}$ per liter, $\mathrm{F} / \mathrm{Pu}=0,0.2$, $0.4,0.6$, and 0.8 ).

\section{Effect of Varying Oxalate on Pu(IV) Spectra (10 Grams Pu per Liter, Oxalate/Pu $=0$ to 0.4)}

Figure 28 shows the effect of increasing oxalate (oxalate/Pu $=0$ to 0.4 ) on the spectra of $\mathrm{Pu}$ (IV) in $4 M$ nitric acid. Increasing levels of oxalate cause only subtle changes in the spectral region between 420 and 475 nanometers.

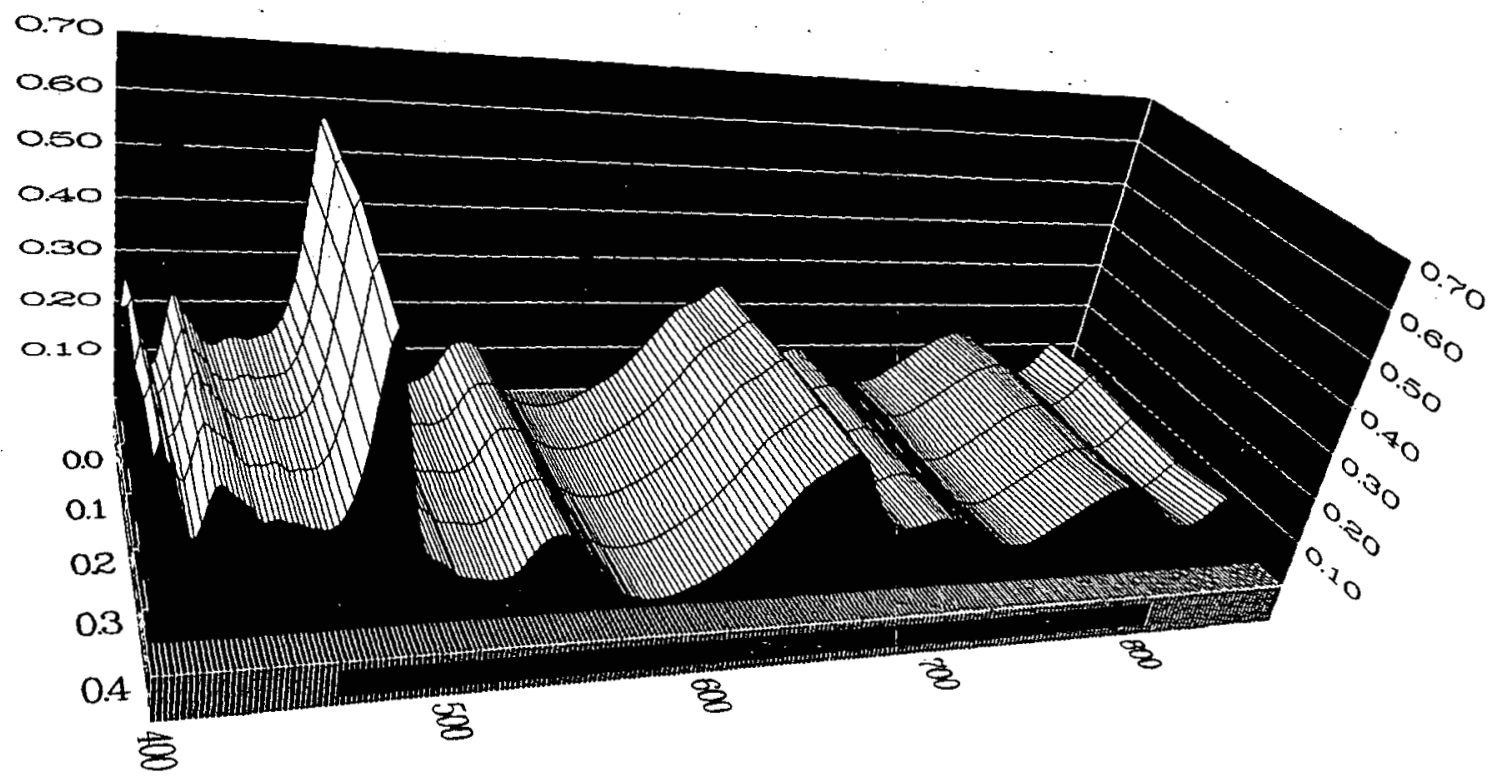

Fig. 28. Effect of oxalate on the spectra of plutonium nitrate solutions (4 M nitric acid, 10 grams $\mathrm{Pu}$ per liter, oxalate/Pu $=0$, $0.1,0.2,0.3$, and 0.4 ). 
Figure 29 shows the effect of increasing oxalate (oxalate/Pu $=0$ to 0.4 ) on the spectra of $\mathrm{Pu}(\mathrm{IV})$ in $5 M$ nitric acid. Increasing levels of oxalate cause only subtle changes in the spectral region between 420 and 475 nanometers.

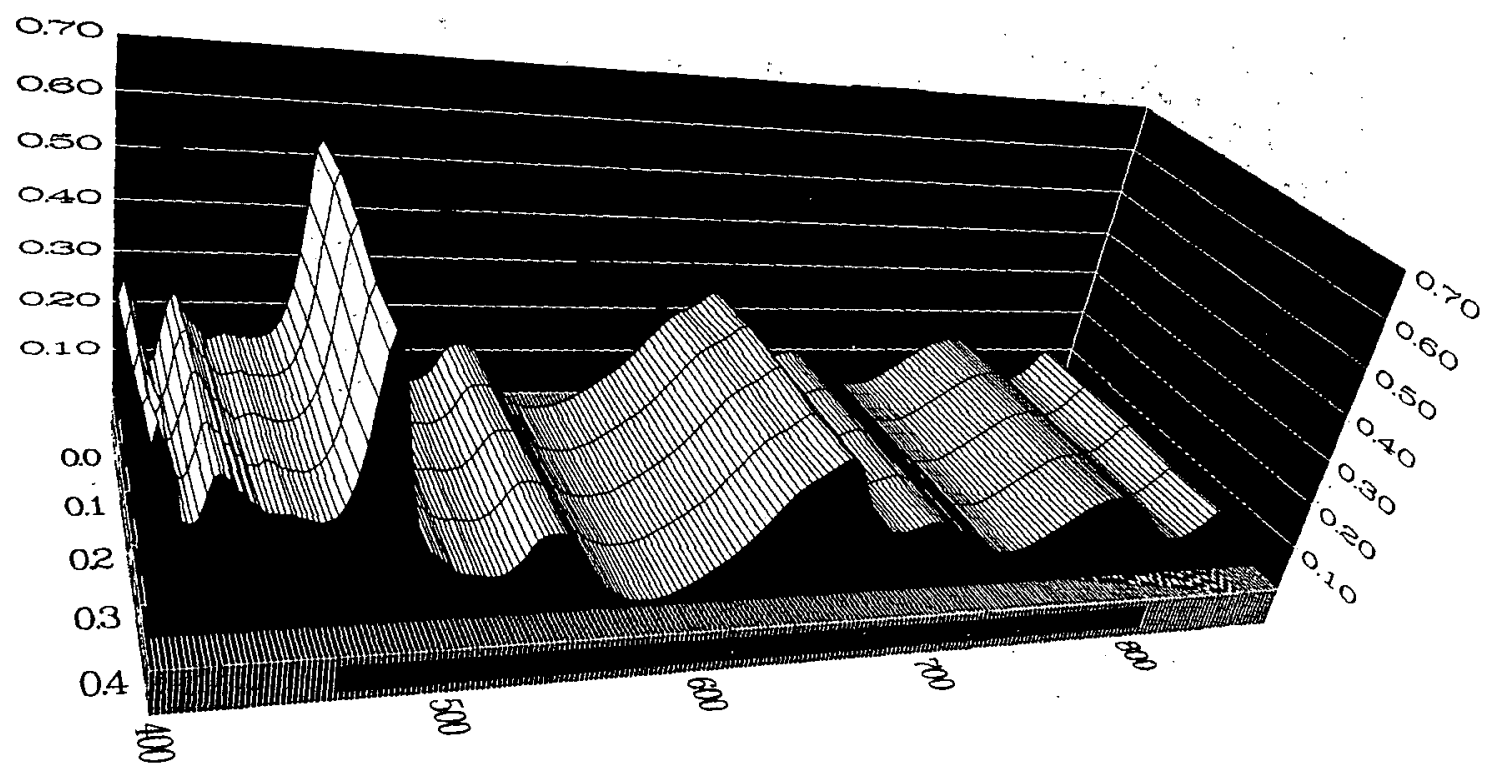

Fig. 28. Effect of oxalate on the spectra of plutonium nitrate solutions (5 $M$ nitric acid, 10 grams $\mathrm{Pu}$ per liter, oxalate/Pu $=0$, $0.1,0.2,0.3$, and 0.4$)$.

Figure 30 shows the effect of increasing oxalate (oxalate/Pu $=0$ to 0.4 ) on the spectra of $\mathrm{Pu}(\mathrm{IV}$ ) in $6 \mathrm{M}$ nitric acid. Increasing levels of oxalate cause only a slight decrease in the 442-nanometer peak and subtle changes in the spectral region between 420 and 475 nanometers.

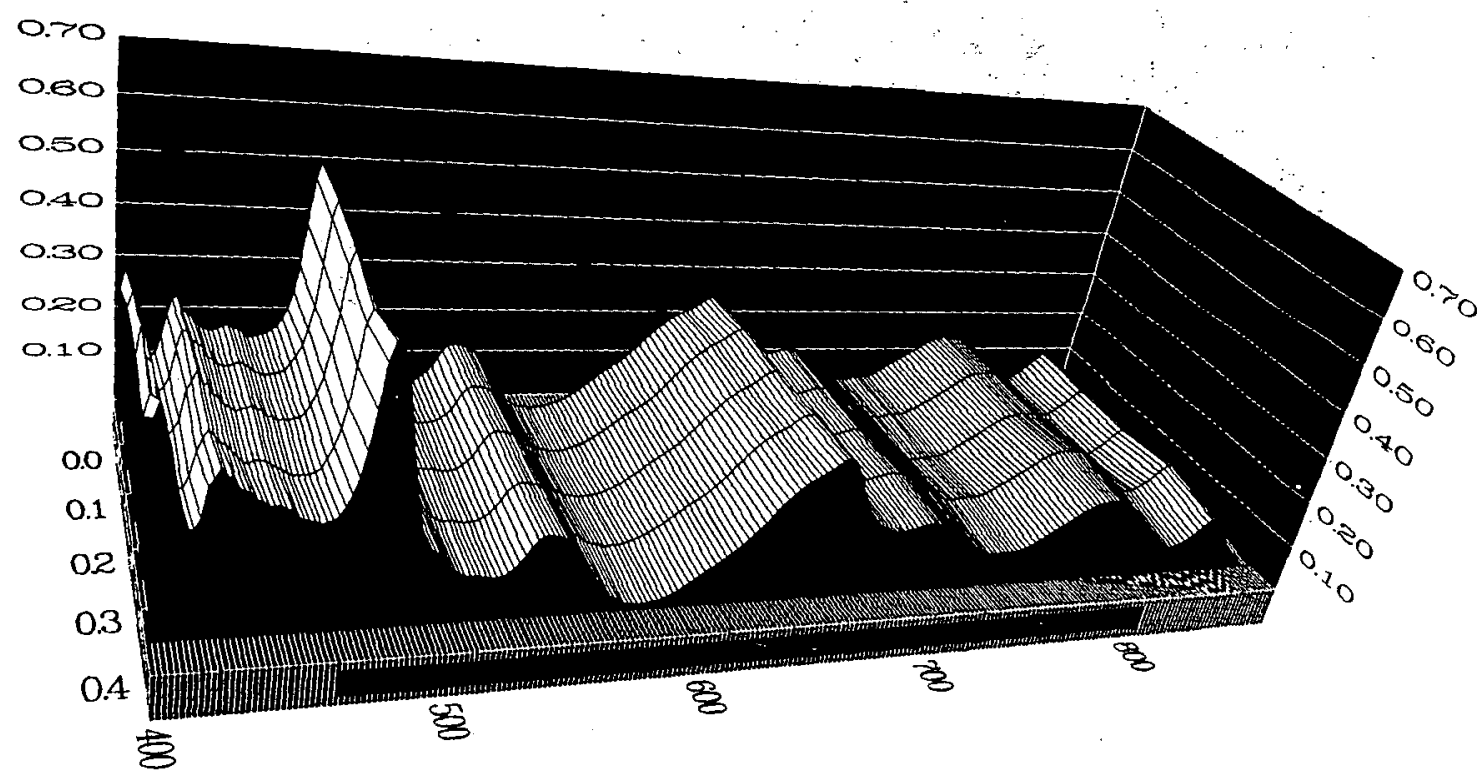

Fig. 30. Effect of oxalate on the spectra of plutonium nitrate solutions (6 $M$ nitric acid, 10 grams $\mathrm{Pu}$ per liter, oxalate/Pu $=0$, $0.1,0.2,0.3$, and 0.4 ). 
Figure 31 shows the effect of increasing oxalate (oxalate/Pu $=0$ to 0.4 ) on the spectra of $\mathrm{Pu}(\mathrm{IV})$ in $7 M$ nitric acid. Increasing levels of oxalate cause only a slight increase in the 420- and 442-nanometer peaks.

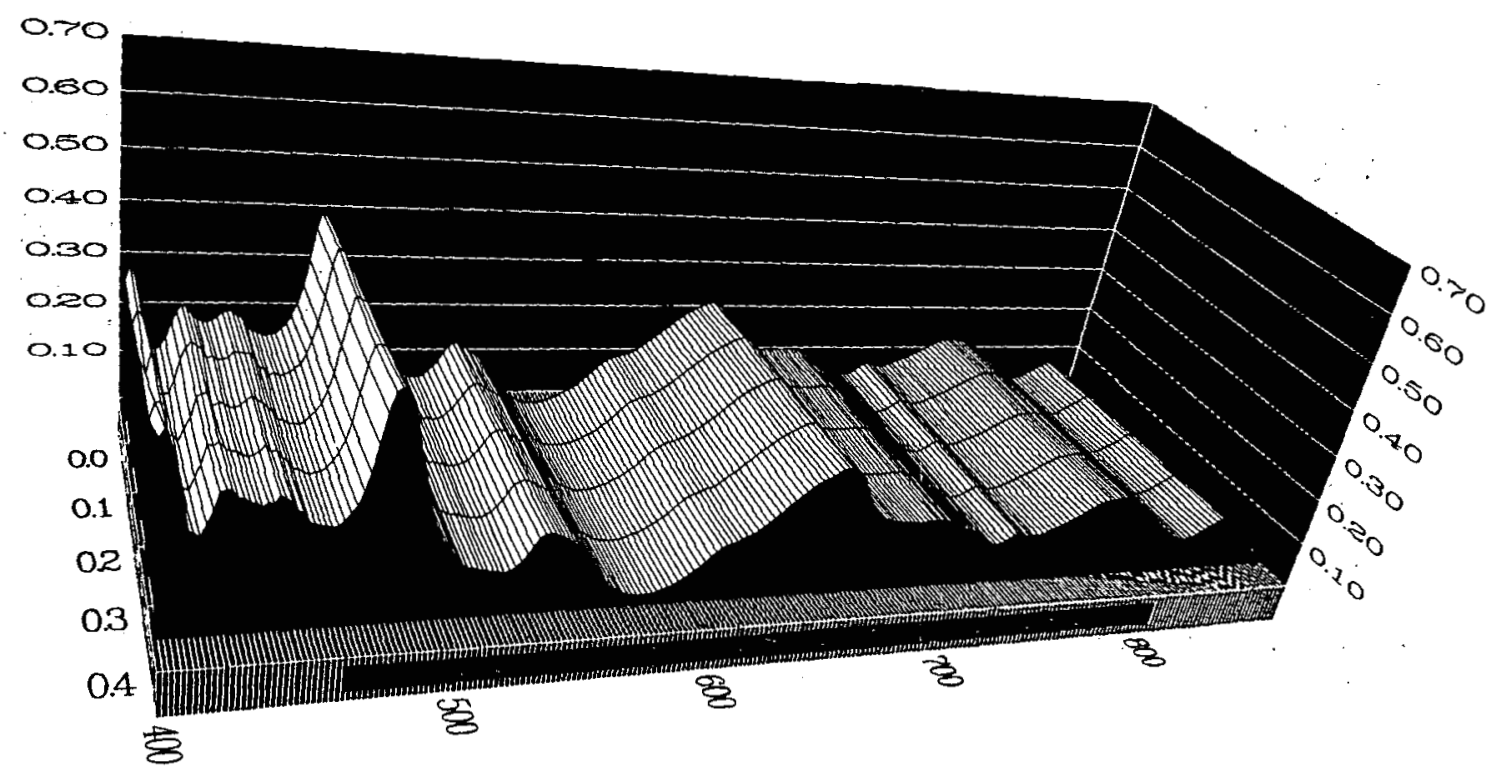

Fig. 31. Effect of oxalate on the spectra of plutonium nitrate solutions ( $7 \mathrm{M}$ nitric acid, 10 grams $\mathrm{Pu}$ per liter, oxalate/Pu $=0$, $0.1,0.2,0.3$, and 0.4$)$.

Figure 32 shows the effect of increasing oxalate (oxalate/Pu $=0$ to 0.4 ) on the spectra of $\mathrm{Pu}(\mathrm{IV})$ in $8 M$ nitric acid. Increasing levels of oxalate cause no significant spectral changes.

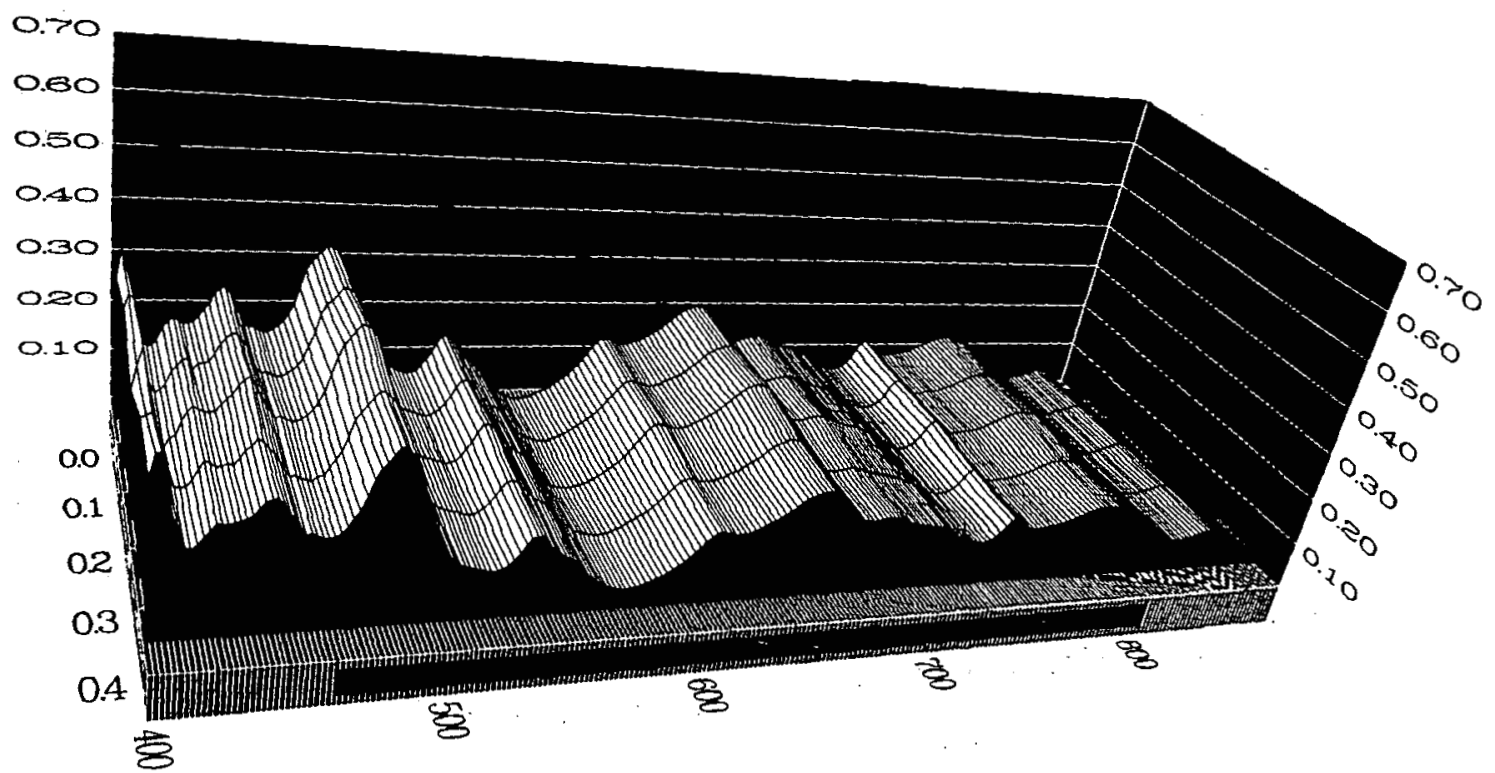

Fig. 32. Effect of oxalate on the spectra of plutonium nitrate solutions ( $8 M$ nitric acid, 10 grams Pu per liter, oxalate/Pu $=0$, $0.1,0.2,0.3$, and 0.4$)$. 
Figure 33 shows the effect of increasing oxalate (oxalate/Pu $=0$ to 0.4 ) on the spectra of $\mathrm{Pu}(\mathrm{IV}$ ) in $9 \mathrm{M}$ nitric acid. Increasing levels of oxalate cause no significant spectral changes.

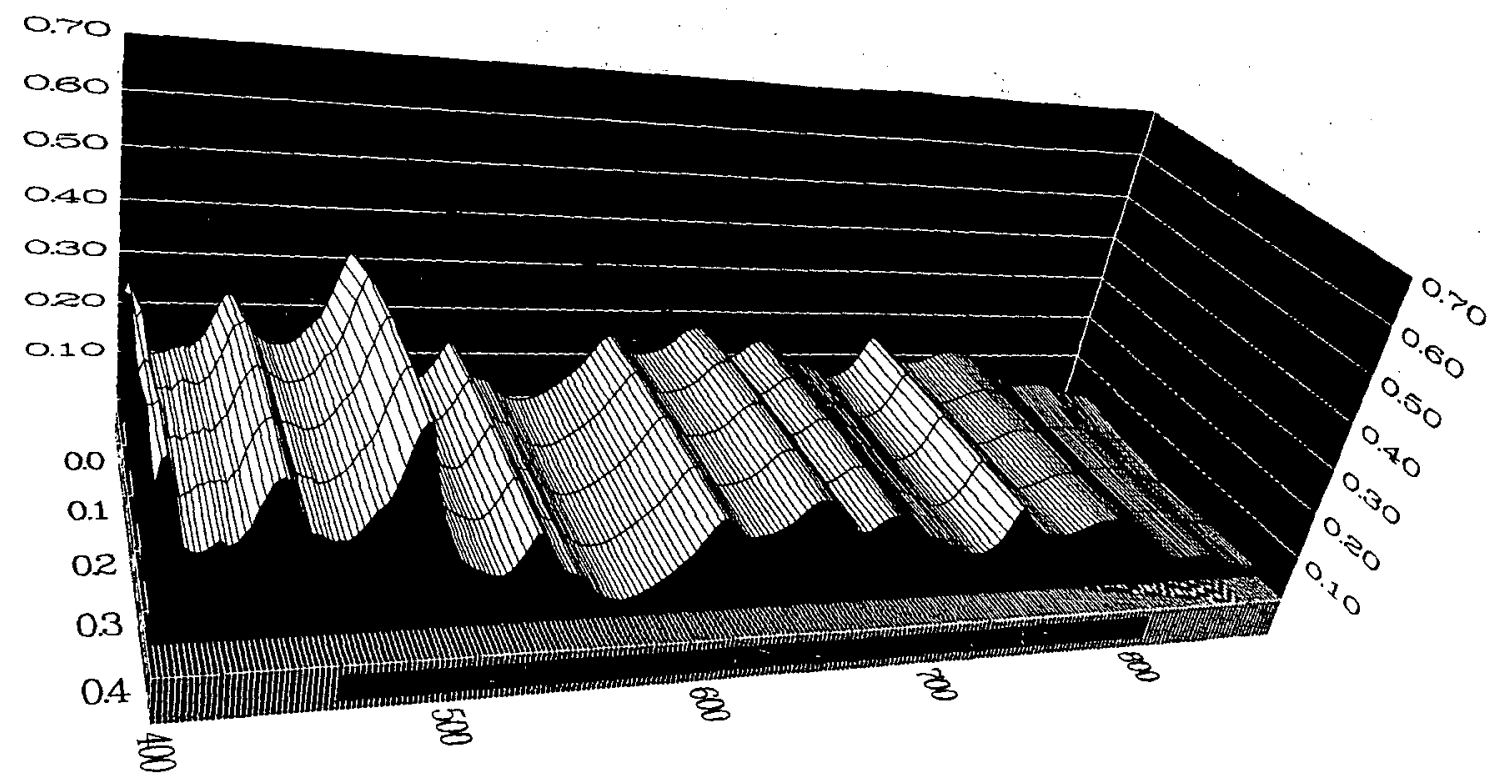

Fig. 33. Effect of oxalate on the spectra of plutonium nitrate solutions ( $9 M$ nitric acid, 10 grams $\mathrm{Pu}$ per liter, oxalate/ $\mathrm{Pu}=0$, $0.1,0.2,0.3$, and 0.4 ).

Figure 34 shows the effect of increasing oxalate (oxalate/ $\mathrm{Pu}=0$ to 0.4 ) on the spectra of $\mathrm{Pu}(\mathrm{IV}$ ) in $10 \mathrm{M}$ nitric acid. Increasing levels of oxalate cause no significant spectral changes.

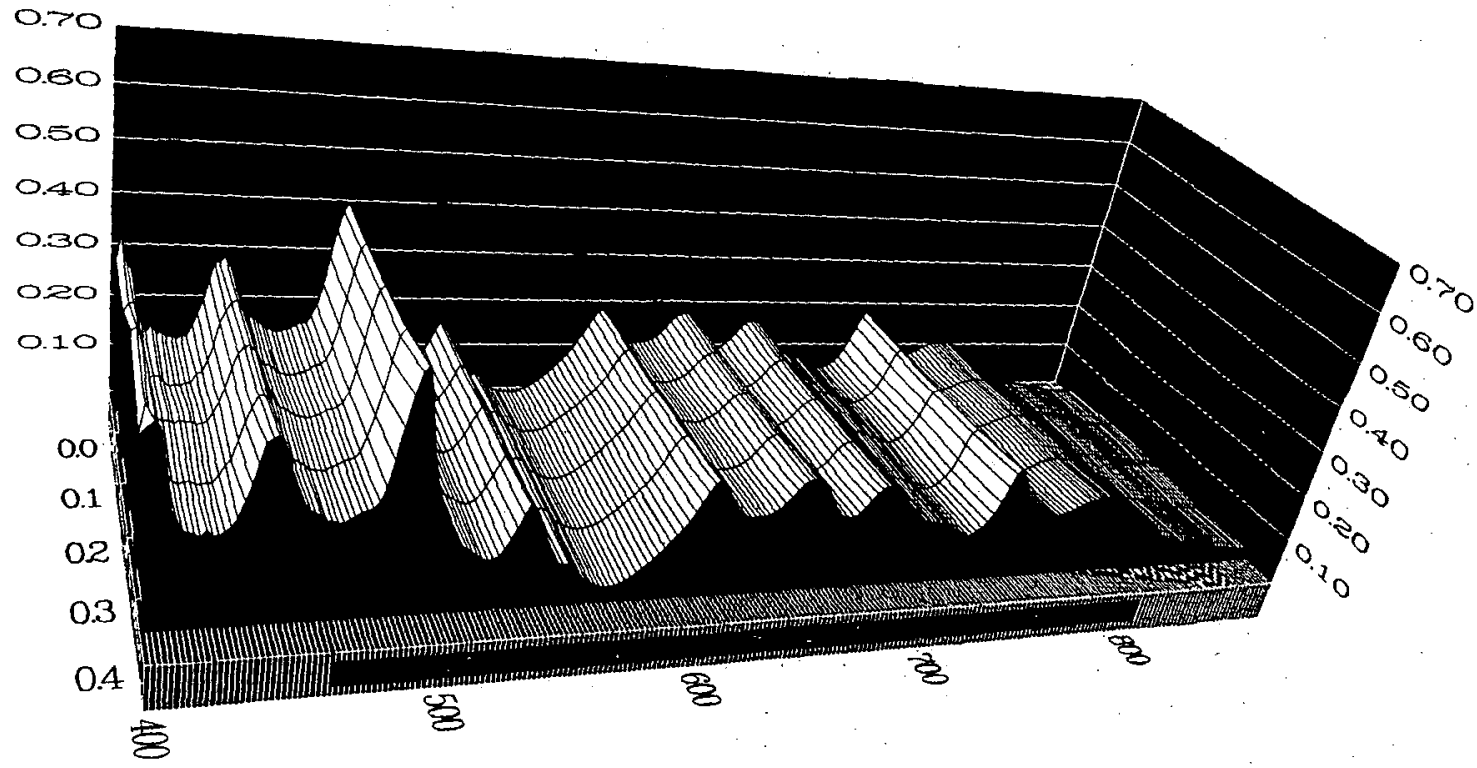

Fig. 34. Effect of oxalate on the spectra of plutonium nitrate solutions (10 $M$ nitric acid, 10 grams $\mathrm{Pu}$ per liter, oxalate/Pu $=0$, $0.1,0.2,0.3$, and 0.4 ). 


\section{SUMMARY}

Spectra of $\mathrm{Pu}(\mathrm{IV})$ solutions are presented for all combinations of two levels of plutonium, seven levels of nitric acid, and five levels of fluoride or five levels of oxalate. Spectral features change significantly in many cases as solution matrix compositions change. The spectral data presented here have been processed by other researchers at the Los Alamos National Laboratory using partial least-squares, pattern recognition, and other sophisticated statistical techniques. The result of this effort is being reported separately. ${ }^{4}$

All solutions used in this study were prepared as mixtures of pure components added in known proportions. These solutions therefore cannot be considered to be the equivalent of actual process solutions that also contain varying quantities of unknown impurity elements. Spectral data reported herein therefore cannot be used directly to evaluate the composition of unknown process solutions. Instead, these data demonstrate that on-line spectrophotometry is sufficiently promising to justify an expanded study that includes actual process solutions.

A spectrophotometric study of actual process solutions has been initiated at Los Alamos; however, the validity of extrapolating the resulting information for use in other processing facilities has not yet been determined. It could well be that differences in process solution composition among nuclear facilities are sufficiently large to require each facility to prepare its own database for calibrating an on-line spectrophotometer. Preliminary results, however, indicate that such an effort might provide the basis for quickly and easily obtaining important near-real-time process-control information that is otherwise unobtainable.

\section{REFERENCES}

1. S. F. Marsh, "The Effect of Fluoride and Aluminum on the Anion Exchange of Plutonium in Nitric Acid," Los Alamos National Laboratory report LA-10999 (July 1987).

2. J. B. Callis, D. L. Illman, and B. R. Kowalski, "Process Analytical Chemistry," Anal. Chem. 59 (9), $624 a-635 a(1987)$.

3. S. F. Marsh and T. D. Gallegos, "Chemical Treatment of Plutonium with Hydrogen Peroxide Before Nitrate Anion Exchange Processing," Los Alamos National Laboratory report LA-10907 (May 1987).

4. L. E. Wangen and W. P. Carey, "A Chemometric Evaluation of the Effect of Fluoride and Oxalate on the VIS-NIR Spectra of $\mathrm{Pu}(\mathrm{IV})-\mathrm{HNO}_{3}$ Solutions," Los Alamos National Laboratory report in preparation. 